\title{
Characterisation of material and connection behaviour in sheathed cold-formed steel wall systems - Part 1: experimentation and data compilation
}

\author{
Constantinos Kyprianou*, Pinelopi Kyvelou, Leroy Gardner, David A. Nethercot \\ Department of Civil and Environmental Engineering, Imperial College London, South Kensington Campus, \\ London $S W 72 A Z, U K$
}

\begin{abstract}
The material and connection behaviour in sheathed cold-formed steel wall systems are investigated in the present paper through experimentation. A total of 103 material and component tests was performed, including six cold-formed steel tensile coupon tests, nine tests on screws in tension, nine tests on screws in shear, 36 material tests on plasterboard and orientated strand board (OSB), 25 pull-through connection tests and 18 push-out (shear) connection tests. The plasterboard and oriented strand board were tested in both compression and tension, as well as both longitudinally and transversely to the production direction of the board. The main objective of the study was to measure and characterise the nonlinear response of all the materials and sheathing-to-steel connection components that are used in typical cold-formed steel wall systems, to support the ongoing and future development of accurate numerical simulations and structural design provisions for such systems. The present paper focuses on the experimental investigation and the collection of existing test data from the literature; a description of all the tests performed and a discussion of the results obtained are provided. The companion paper focuses on the establishment and assessment of predictive models to describe the responses of the material and connection components.
\end{abstract}

Keywords: cold-formed steel; experiments; OSB; plasterboard; pull-through; push-out; screw connectors; sheathing 


\section{Introduction}

Wall systems built using cold-formed steel members and sheathed with boards such as plasterboard and orientated strand board (OSB), are commonplace in the construction industry and are being increasingly used as load bearing elements. Cold-formed steel frames have been employed successfully as an alternative to timber and masonry construction for low and medium rise buildings, principally due to their speed of construction, lightweight nature and sound structural performance. Whereas traditionally the contribution of the sheathing to the strength and stiffness of cold-formed steel columns and walls has been ignored, it has been shown by several researchers [1-3] that sheathing can offer effective bracing to columns, provided a suitably strong and stiff inter-connection exists. Thus, it is recognized that more efficient design can be achieved if the influence of the sheathing board is taken into account. First though, a thorough understanding of the material behaviour of the individual components and of the interaction between them is required. Physical experiments to characterise the stress-strain response of the constituent materials and the load-slip connection performance of typical cold-formed steel wall systems are presented in this paper. This study is part of a wider research programme into the behaviour and design of sheathed cold-formed steel wall systems under combined compression and bending.

Experimental studies into the stress-strain response of cold-formed steel, which is typically more rounded than that of conventional hot-rolled steel, due to the influence of the cold-forming process, have been widely reported in the literature [4]. Studies into the stress-strain response of sheathing material are, however, more scarce. A detailed experimental study into the mechanical properties of various types of plasterboard was reported in [7], while further test results were presented in [8]. Similarly, results of tensile and compressive tests on OSB were presented in 9 and [10. The key properties obtained from tests on OSB were also presented in 11, along with an empirical material model for use in numerical simulations.

\footnotetext{
* Corresponding author

Email addresses: constantinos.kyprianou08@imperial.ac.uk (Constantinos Kyprianou, pinelopi.kyvelou11@imperial.ac.uk (Pinelopi Kyvelou), leroy.gardner@imperial.ac.uk (Leroy Gardner), d.nethercot@imperial.ac.uk (David A. Nethercot)
} 
The nonlinear interaction between the board and the column in cold-formed steel wall systems, as well as the failure mode of the connectors, are dependent on the arrangement, type and material characteristics of the various system components. Past studies [12 16] behaviour of cold-formed steel-to-sheathing connections are reported in Section 4 . In Section 5. the results from corresponding material and connection tests reported in the literature are collected and compared to those obtained in the present study. In the companion paper [28], the combined dataset is analysed and used to underpin the development of predictive 55 have focused primarily on the shear characteristics of the interface owing to its importance when the studied wall systems are designed to act as diaphragms. Individual shear connection tests, featuring OSB and plasterboard as the sheathing and a range of steel thicknesses and screw connector sizes, were reported in [14, 17, 22]. Experimental studies into the shear response of sheathing-to-cold-formed steel connections have also been conducted for various other types of board material, including cement based boards [18, 23], calcium silicate boards [22, 24], fibre cement boards [25] and Bolivian manganese boards [22].

When sheathed cold-formed steel members are subjected to compression, bending or a combination of the two, the forces that develop along the interface between the steel and sheathing can cause excessive separation (pull-through failure) or slip (shear failure) between the two elements, if the strength and stiffness of the connection is not sufficient. A combination of pull-through and bearing failures for connections in assemblies with plasterboard and cold-formed steel were reported in [26, 27]. Although screw and sheathing manufacturers tend to report characteristic pull-through capacities, experimental data on screws failing purely by pull-through are very limited.

An experimental investigation into the material response of the different components used to form a typical sheathed cold-formed steel wall system, as well as the load-slip behaviour of the employed fasteners in pull-through and shear are presented herein. In Section 2, a description of the material and screw connector tests, along with the obtained results, is provided, while the results of the pull-through tests featuring various arrangements of plasterboards and OSB, are presented in Section 3. Push-out tests, examining the shear models. 


\section{Material and component testing}

Material tests were carried out to determine the stress-strain behaviour of the cold-formed steel and sheathing material used in the pull-through and shear tests, while experiments to determine the ultimate load-carrying capacity of the employed screw connectors were also undertaken. Testing was carried out in the Structures Laboratory of Imperial College London under controlled temperature and humidity conditions, in the range of $20-24{ }^{\circ} \mathrm{C}$ and 30 $50 \%$ respectively.

\subsection{Cold-formed steel}

Tensile coupon tests were conducted to determine the engineering stress-strain behaviour of the cold-formed steel material of grade S450 galvanised with Z275 zinc coating. Four coupons were extracted longitudinally from the web of $150 \mathrm{~mm}$ deep lipped channel sections of $1.2 \mathrm{~mm}$ and $2.0 \mathrm{~mm}$ nominal thickness (two coupons for each thickness) while, for each thickness, one coupon was also extracted from the coil prior to section forming. The nominal dimensions of the tensile coupons are illustrated in Figure 1.

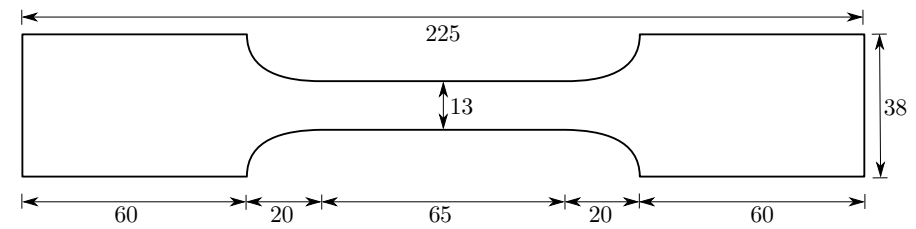

Figure 1: Nominal dimensions of steel tensile coupons (in $\mathrm{mm}$ )

\subsubsection{Testing tensile cold-formed steel coupons}

The tensile coupons were tested in accordance with BS EN ISO 6892 [29] where an axial strain rate of $0.00007 \mathrm{~s}^{-1}$ was initially applied and gradually increased to $0.00025 \mathrm{~s}^{-1}$ after the $0.2 \%$ proof stress had been reached through three intermediate strain rate steps. A 150 $\mathrm{kN}$ Instron 5984 testing machine was used, along with the Bluehill data acquisition system, collecting data every second.

To capture the strains at the early stages of testing accurately, two strain gauges were mounted on each coupon (one per side). An optical video extensometer with a gauge length 


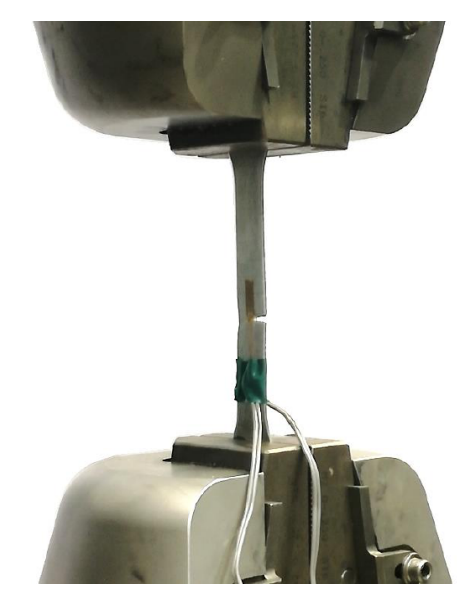

(a) Tensile coupon at point of failure

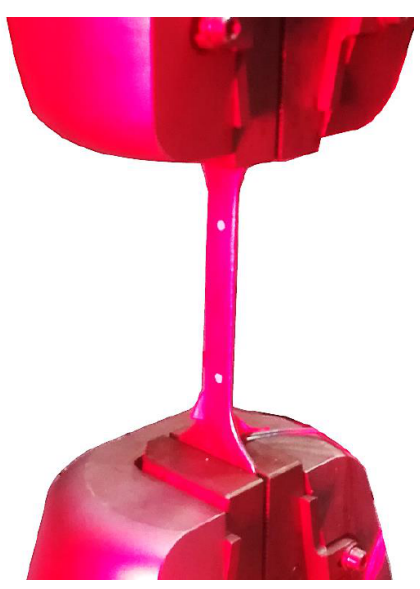

(b) Optical extensometer reading during testing

Figure 2: Test setup for cold-formed steel tensile coupons

of $50 \mathrm{~mm}$ was also used as an additional method of capturing strain measurements. Illustrations of the strain gauges and the optical extensometer are shown in Figure 2.

\subsubsection{Results of tensile cold-formed steel coupons}

The key measured material properties of the tested coupons are presented in Table 1 while the full stress-strain curves are illustrated in Figure 3. The notation of the coupons begins with the letter $\mathrm{C}$, followed by the nominal thickness of the material $(\times 10)$ in $\mathrm{mm}$ and then, either the number of the test for the repeated tests or the word "coil" for the samples taken from the coil. In Table 1, $E$ is the Young's modulus, $\sigma_{0.2}$ is the $0.2 \%$ proof stress (considered as the yield strength), $\sigma_{1.0}$ is the $1 \%$ proof stress, $\sigma_{u}$ is the ultimate strength, $\varepsilon_{s h}$ is the strain at the end of the yield plateau, $\varepsilon_{u}$ is the strain at $\sigma_{u}, \varepsilon_{f}$ is the elongation at fracture measured over the standard gauge length [29] and $n$ and $m$ are the two-stage Ramberg-Osgood strain hardening exponents [4]. The average measured material properties and thickness $t_{s}$ for the nominally $1.2 \mathrm{~mm}$ and $2.0 \mathrm{~mm}$ thick cold-formed steel coupons are presented in Table 2 .

\subsection{Plasterboard}

Material tests were performed on standard type gypsum-based plasterboard, designated as Type A in accordance with EN 520 [30], of average measured thickness and density of 12.5 
Table 1: Material properties obtained from tensile coupon tests on cold-formed steel

\begin{tabular}{cccccccccc}
\hline Coupon ID & $E(\mathrm{GPa})$ & $\sigma_{0.2}(\mathrm{MPa})$ & $\sigma_{1.0}(\mathrm{MPa})$ & $\sigma_{u}(\mathrm{MPa})$ & $\varepsilon_{s h}(\%)$ & $\varepsilon_{u}(\%)$ & $\varepsilon_{f}(\%)$ & $n$ & $m$ \\
\hline C12-coil & 207 & 502 & 533 & 539 & - & 3.25 & 7.31 & 8.5 & 4.0 \\
C12-1 & 207 & 499 & 528 & 532 & - & 3.44 & 7.03 & 8.9 & 4.0 \\
C12-2 & 205 & 500 & 527 & 532 & - & 3.28 & 6.56 & 8.7 & 4.0 \\
C20-coil & 210 & 519 & 516 & 589 & 2.05 & 10.5 & 17.9 & - & - \\
C20-1 & 203 & 509 & 514 & 588 & 1.92 & 9.77 & 16.2 & - & - \\
C20-2 & 205 & 518 & 523 & 591 & 1.71 & 9.75 & 16.0 & - & - \\
\hline
\end{tabular}

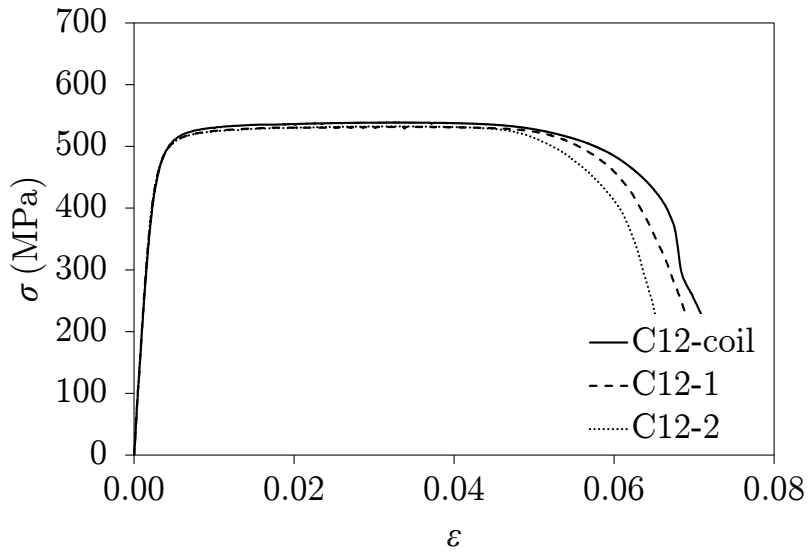

(a) $1.2 \mathrm{~mm}$ thickness

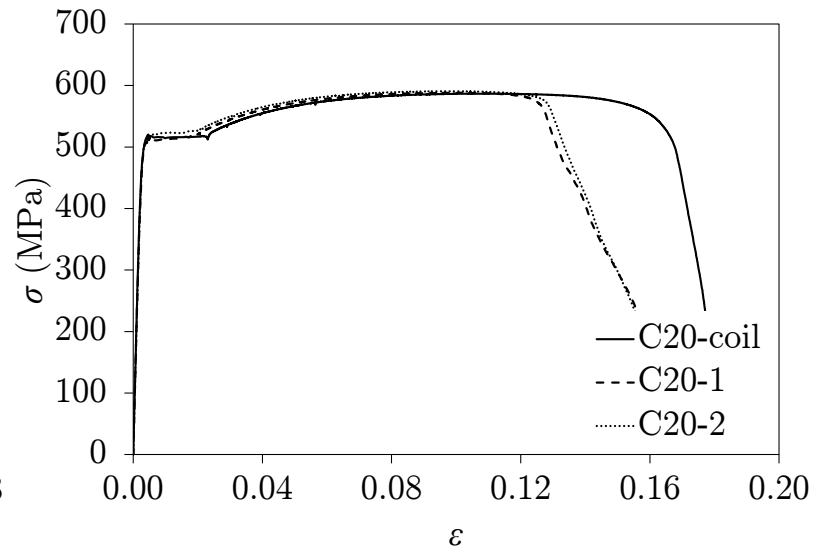

(b) $2.0 \mathrm{~mm}$ thickness

Figure 3: Stress-strain curves of tensile coupons of (a) $1.2 \mathrm{~mm}$ and (b) $2.0 \mathrm{~mm}$ thickness

Table 2: Average material properties obtained from tensile coupon tests on cold-formed steel

\begin{tabular}{cccccccccc}
\hline$t_{s}(\mathrm{~mm})$ & $E(\mathrm{GPa})$ & $\sigma_{0.2}(\mathrm{MPa})$ & $\sigma_{1.0}(\mathrm{MPa})$ & $\sigma_{u}(\mathrm{MPa})$ & $\varepsilon_{s h}(\%)$ & $\varepsilon_{u}(\%)$ & $\varepsilon_{f}(\%)$ & $n$ & $m$ \\
\hline 1.19 & 206 & 500 & 529 & 534 & - & 3.32 & 6.97 & 8.7 & 4.0 \\
1.99 & 206 & 515 & 518 & 589 & 1.89 & 10.0 & 16.7 & - & - \\
\hline
\end{tabular}


$\mathrm{mm}$ and $665 \mathrm{~kg} / \mathrm{m}^{3}$ respectively. A standard type A plasterboard is composed of a gypsum based core encased and bonded to durable paper on one face to which suitable plastering and finishes may be applied, and to a much coarser and weaker paper lining on the other side which is not intended to carry any decoration. This type of board is typically used as sheathing for metal frame stud walls and ceilings.

\subsubsection{Tensile and compressive plasterboard tests}

Tensile and compressive material tests were carried out to determine the stress-strain curves and key material properties of the examined plasterboard. The tests were performed in accordance with EN 789 [31], which provides guidance on determining the mechanical properties of wood-based panels; this standard was used in preference to EN 520 [30], which is a specification for gypsum plasterboard, since more extensive information on the determination of compressive and tensile properties is provided [7]. Tests were carried out on specimens loaded both longitudinally and transversely to the production direction of the board. Five tensile tests and four compressive tests were performed for each direction; 18 plasterboard material experiments were carried out in total.

The dimensions of the tensile and compressive coupons are shown in Figures 4 (a) and 4 (b) respectively. Each compressive coupon comprised four boards glued together using a spray adhesive which was non-absorbent and hence would not be expected to alter the mechanical properties of the plasterboard. For the tensile coupons, failure occurred within the parallel length - see Figure 5 (a). For the compressive coupons, load was introduced through a hemispherical bearing, seated on a steel plate, to achieve a uniform applied stress, as shown in Figure 5 (b). The coupons were tested under displacement control, at a rate of $0.25 \mathrm{~mm} / \mathrm{min}$, using a $150 \mathrm{kN}$ Instron 5984 testing machine, while the Bluehill data acquisition system was used to record data every second.

Although $50 \mathrm{~mm}$ long strain gauges, typically used for concrete samples, were initially considered, finally these were not used due to difficulties in attaching them to the plasterboard surface. Hence, for capturing accurately the overall strain field of the examined systems, digital image correlation (DIC) was employed. A speckle pattern was first applied 
to all specimens to allow the use of DIC. The non-contact optical DIC system was used with two cameras tracking the same speckled pattern from two different angles. The DaVis V.10 [32] software was employed to record and process the images captured at a frequency of 2 Hz. One linear variable displacement transducer (LVDT) was also mounted on the reverse side of each specimen, out of view of the DIC, as shown in Figure 5, providing a second method of measuring the overall deformation of the specimen. The LVDT measurements were recorded using the Bluehill data acquisition system at one second intervals.

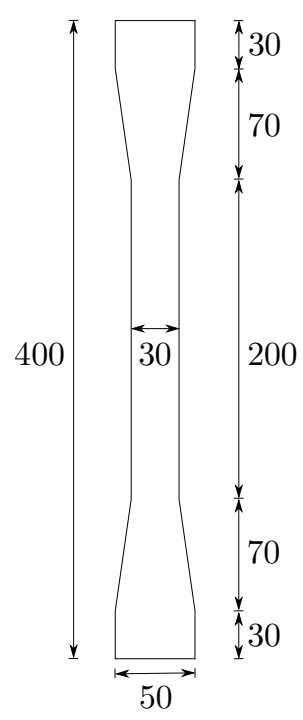

(a) Dimensions of tensile coupons in $\mathrm{mm}$

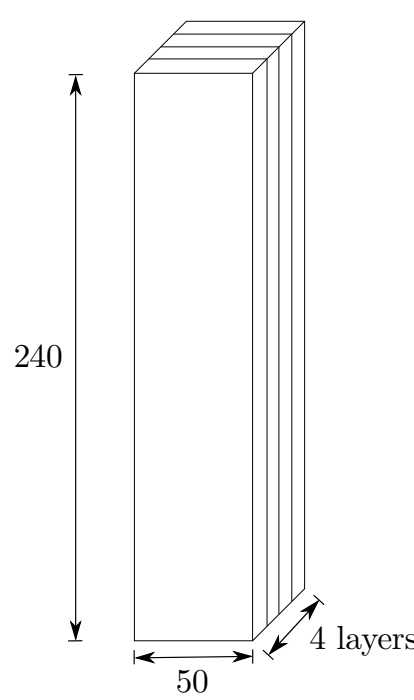

(b) Dimensions of compressive coupons in $\mathrm{mm}$

Figure 4: Dimensions of (a) tensile and (b) compressive plasterboard coupons 


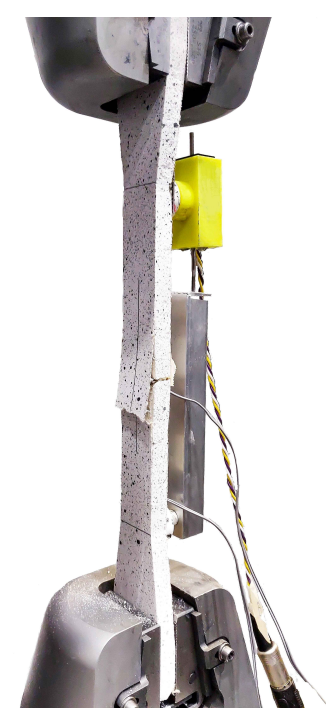

(a) Plasterboard tensile coupon test

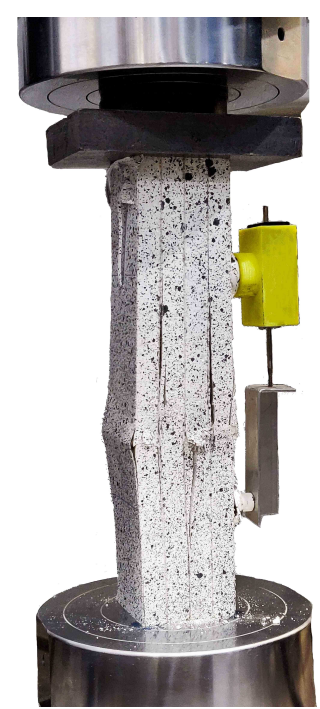

(b) Plasterboard compression coupon test

Figure 5: Test setup for (a) tensile and (b) compressive material tests on plasterboard

\subsubsection{Results of material tests on plasterboard}

Loading of all specimens was continued until failure could be clearly observed. The adopted notation for the tensile and compressive plasterboard coupons begins with PL, denoting plasterboard, following by the letter $\mathrm{t}$ for tension or $\mathrm{c}$ for compression, then the capital letter $\mathrm{L}$ or $\mathrm{T}$ to designate longitudinal or transverse respectively and, finally, the test number.

Failure of the tensile specimens was marked by a sharp decrease in load, together with the development of a distinct horizontal crack in both the internal gypsum and the outer paper surfaces, perpendicular to the direction of the applied load, as shown in Figures 5 (a) and 8 (b). The key measured properties of the plasterboard from the tensile tests - the Young's modulus in tension $E$, the ultimate tensile stress $f_{u}$ and the corresponding strain $\varepsilon_{u}$ are provided in Table 3. The stress-strain curves for the longitudinal and transverse tensile coupons, shown in Figure 7 (a) and (b) respectively, generally exhibit a rounded profile with no distinct yield point. Two transverse specimens, T1 and T3, displayed initial peaks before dropping to the rounded stress-strain responses exhibited by other specimens; this behaviour may relate to the weaker paper not failing until after the internal gypsum core 
had fractured or a delay in the fracture of the internal gypsum core. Note that these two sharp peaks were ignored when determining the ultimate tensile strength $f_{u}$, as indicated in Table 3 .

Two distinct modes of failure were observed for the compressive plasterboard specimens: (a) a diagonal shear plane across the four plasterboards and (b) crushing of the material, with the outer boards folding outwards and vertical cracks forming within the boards, both of which can be seen in Figure 10. Failure appeared to be essentially simultaneous across the four boards for both modes of failure. The profile of the stress-strain curves obtained from the compression tests was consistent for both the longitudinal and transverse specimens, featuring an elastic region, some loss of stiffness, attainment of the peak stress and then a gradual decrease in stress. The key measured properties of the plasterboard from the compression tests - the Young's modulus in compression $E$, the ultimate compressive strength $f_{u}$, the corresponding strain $\varepsilon_{u}$ and the strain $\varepsilon_{u, 0.8}$ at which the post peak stress level had dropped to $80 \%$ of the ultimate strength, are reported in Table 4 . The notation defining the key points on the material stress-strain is illustrated in Figure 6

While the difference between the stiffness of the longitudinal and transverse samples was small for both the tensile and compressive tests, a difference of $30 \%$ was observed between the values of stiffness in tension and compression. In terms of strength, the ultimate compressive stress was similar in the two loading directions (transverse and longitudinal), while the ultimate tensile stress showed far greater variation, with higher strengths in the longitudinal direction. 


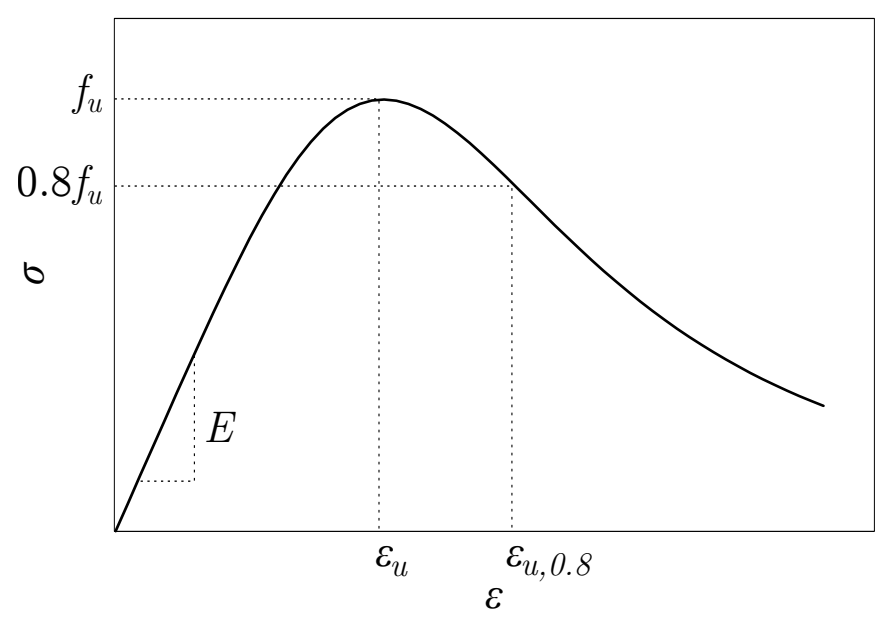

Figure 6: Notation defining key points on material stress-strain curves

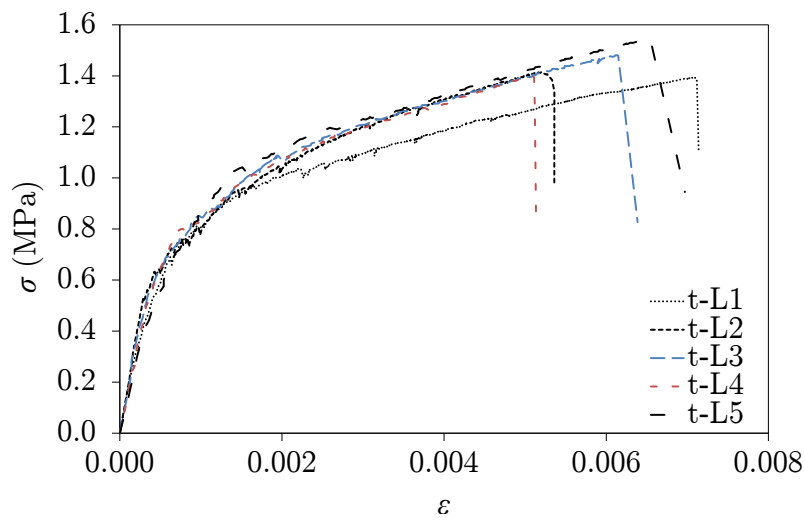

(a) Longitudinal

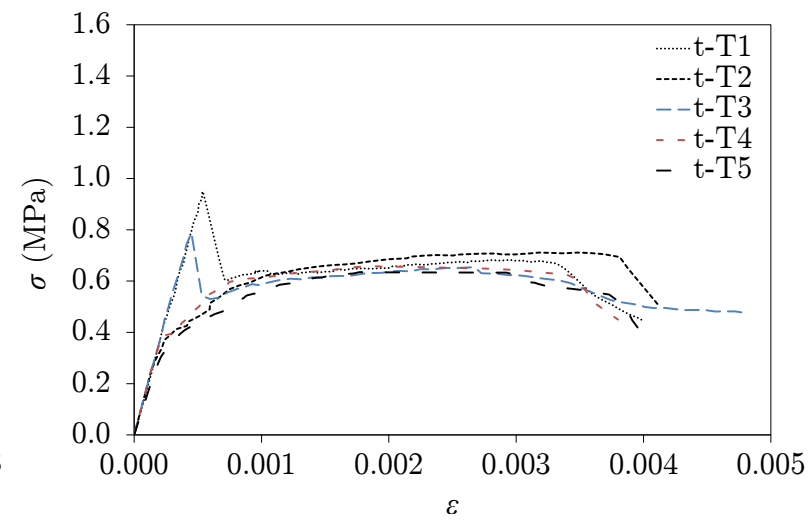

(b) Transverse

Figure 7: Stress-strain curves obtained from plasterboard tensile coupon tests in (a) the longitudinal and (b) the transverse directions 


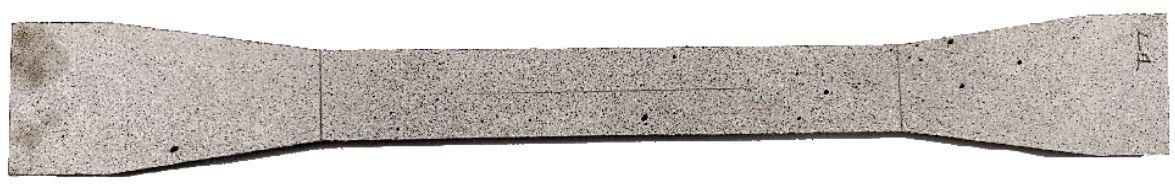

(a) Plasterboard tensile coupon before test

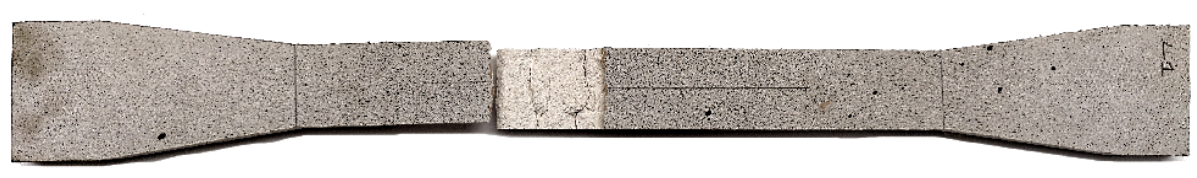

(b) Plasterboard tensile coupon after test

Figure 8: Typical plasterboard tensile coupon (a) before and (b) after test

Table 3: Key tensile material properties from plasterboard coupon tests

\begin{tabular}{ccccc}
\hline Loading direction & Specimen & $E(\mathrm{MPa})$ & $f_{u}(\mathrm{MPa})$ & $\varepsilon_{u}(\%)$ \\
\hline & PL-t-L1 & 1580 & 1.39 & 0.74 \\
& PL-t-L2 & 1880 & 1.41 & 0.54 \\
& PL-t-L3 & 1770 & 1.48 & 0.62 \\
Longitudinal & PL-t-L4 & 1630 & 1.40 & 0.51 \\
& PL-t-L5 & 1380 & 1.54 & 0.65 \\
\cline { 2 - 5 } & Average & 1650 & 1.45 & 0.61 \\
& COV & 0.10 & 0.05 & 0.15 \\
\hline \multirow{5}{*}{ Transverse } & PL-t-T1 & 1780 & $0.68^{*}$ & 0.37 \\
& PL-t-T2 & 1620 & 0.71 & 0.41 \\
& PL-t-T3 & 1850 & $0.65^{*}$ & 0.37 \\
& PL-t-T4 & 1720 & 0.66 & 0.36 \\
& PL-t-T5 & 1390 & 0.63 & 0.38 \\
\cline { 2 - 5 } & Average & 1670 & 0.67 & 0.38 \\
& COV & 0.11 & 0.04 & 0.05 \\
\hline
\end{tabular}

* Sharp peaks ignored in the determination of $f_{u}$ 


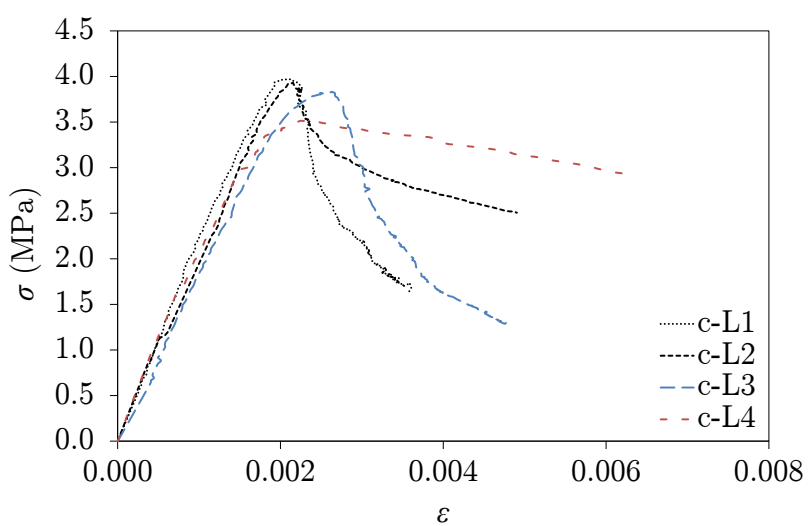

(a) Longitudinal

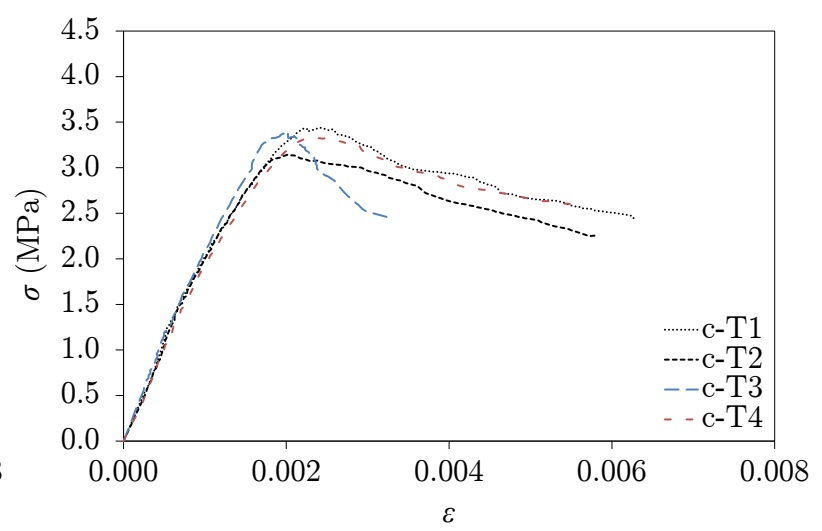

(b) Transverse

Figure 9: Stress-strain curves obtained from compressive coupon tests on plasterboard in (a) the longitudinal and (b) the transverse directions
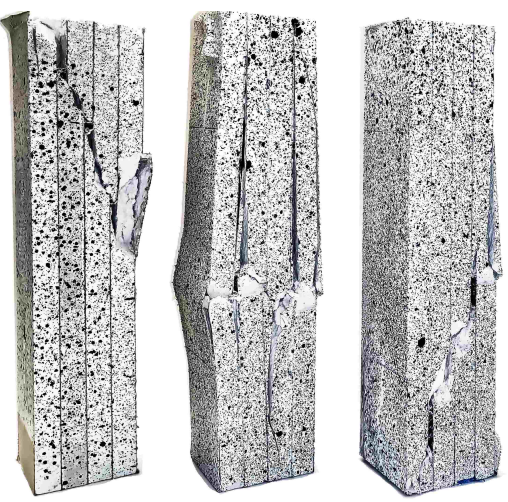

(a) Longitudinal
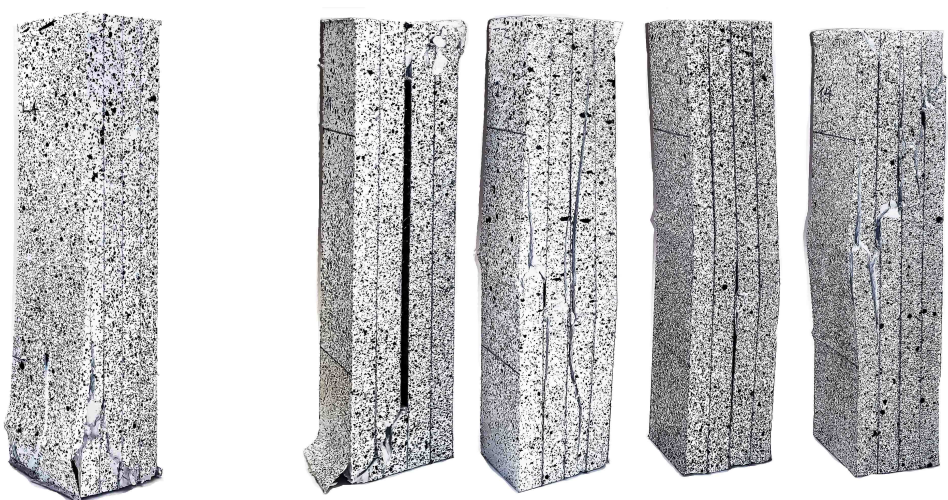

(b) Transverse

Figure 10: Failure modes observed in compressive coupon tests on plasterboard in (a) the longitudinal and (b) the transverse directions 
Table 4: Key compressive material properties from plasterboard coupon tests

\begin{tabular}{cccccc}
\hline Loading direction & Specimen & $E(\mathrm{MPa})$ & $f_{u}(\mathrm{MPa})$ & $\varepsilon_{u}(\%)$ & $\varepsilon_{u, 0.8}(\%)$ \\
\hline \multirow{5}{*}{ Longitudinal } & PL-c-L1 & 2210 & 3.97 & 0.21 & 0.24 \\
& PL-c-L2 & 2130 & 3.93 & 0.22 & 0.27 \\
& PL-c-L3 & 1790 & 3.83 & 0.26 & 0.30 \\
& PL-c-L4 & 2290 & 3.51 & 0.22 & 0.69 \\
\cline { 2 - 6 } & Average & 2110 & 3.81 & 0.23 & 0.37 \\
& COV & 0.10 & 0.05 & 0.11 & 0.57 \\
\hline \multirow{5}{*}{ Transverse } & PL-c-T1 & 2120 & 3.44 & 0.25 & 0.46 \\
& PL-c-T2 & 2130 & 3.14 & 0.21 & 0.46 \\
& PL-c-T3 & 2170 & 3.39 & 0.20 & 0.28 \\
& PL-c-T4 & 2080 & 3.33 & 0.26 & 0.50 \\
\cline { 2 - 6 } & Average & 2130 & 3.33 & 0.23 & 0.42 \\
& COV & 0.02 & 0.04 & 0.13 & 0.24 \\
\hline
\end{tabular}

\subsection{Oriented strand board (OSB)}

Orientated strand boards are multi-layered boards made from strands of wood bonded together with adhesive. In the external layers, the strands are aligned while in the internal layers the strands tend to be either randomly orientated or perpendicular to the direction of the external layers. As part of the experimental programme presented herein, material tests were carried out on type OSB/3 oriented strand boards, suitable for load-bearing use in humid conditions, as indicated in EN 300 [33] and EN 1995-1-1 [34]. The tested material had on average measured thickness of $11 \mathrm{~mm}$ and a density of $590 \mathrm{~kg} / \mathrm{m}^{3}$.

\subsubsection{Tensile and compressive tests on OSB material}

Determination of the tensile and compressive mechanical properties of the OSB was conducted in accordance with the provisions of EN 789 [31]. Similarly to the approach followed for the plasterboard material testing, tests were carried out on specimens cut both 
longitudinally and transversely to the production direction of the board. In total, ten tensile and eight compressive OSB material tests were carried out.

The dimensions of both the tensile and compressive coupons were the same as those of the plasterboard coupons illustrated in Figure 4. The employed test setup (see Figure 11) and procedure were also the same. Digital image correlation with two cameras recording images at a frequency of $2 \mathrm{~Hz}$ was employed for measuring the strains, while the acquisition of load and strain measurements was carried out using the Bluehill data acquisition system and DaVis v.10 [32] respectively.

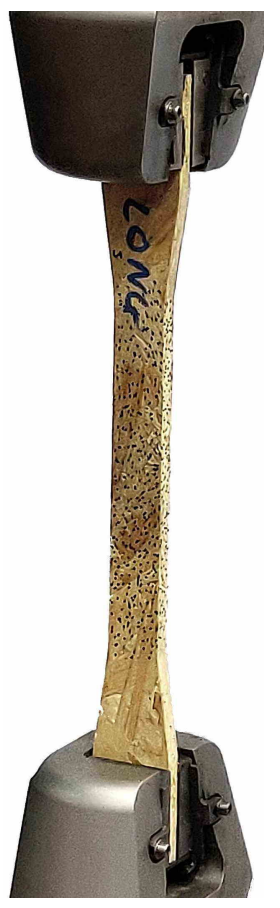

(a) Tensile OSB coupon test

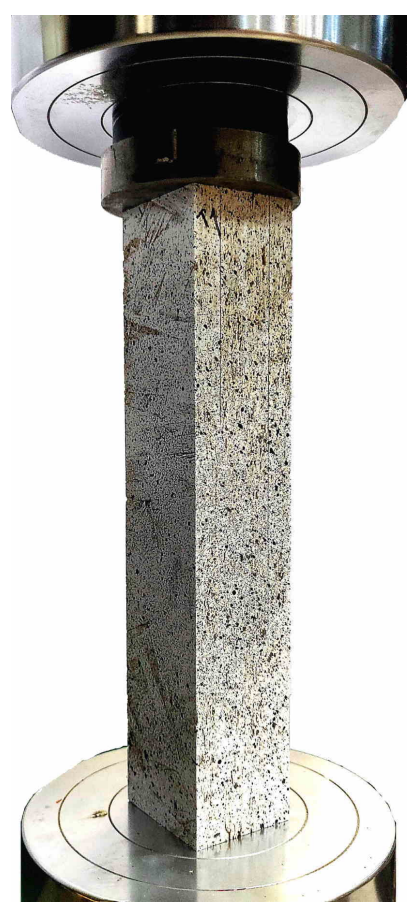

(b) Compression OSB coupon test

Figure 11: Test setup for OSB coupons in (a) tension and (b) compression

\subsubsection{Results of OSB material tests}

All tests were carried out until failure of the coupons could be observed. The notation of the OSB tensile and compressive coupons begins with the capital letters OSB; this is followed by the letter $\mathrm{t}$ for tension or c for compression, then the capital letter $\mathrm{L}$ or $\mathrm{T}$ to designate the coupons as either longitudinal or transverse and finally the number of the test. 
Sudden failure without any significant plastic deformation was exhibited by all tensile coupons, as apparent in the stress-strain curves depicted in Figure 12. The failure mode of a typical tensile coupon is shown in Figure 13. The key measured material properties are listed in Table 5. The values of the Young's modulus and tensile strength of the longitudinal coupons were found to be, on average, about $40 \%$ and $70 \%$ higher, respectively than those of the transverse coupons. This is attributed to the direction of production of the OSB panels, with the orientation of the strands parallel to the loading direction having a beneficial influence on the material response.

The stress-strain curves of the coupons tested in compression were rounded, with a gradual decrease in stiffness prior to the peak strength and a gradual post peak softening response - see Figure 14. The two main failure modes that were observed for both sets of coupons (i.e. longitudinal and transverse) were diagonal shear and folding out of the external surfaces resulting in horizontal cracks between the boards; these are shown in Figure 14. The key measured compressive material properties are reported in Table 6. Similarly to in tension, the Young's modulus in compression was about $40 \%$ higher in the longitudinal direction than in the transverse direction. However, the ultimate compressive strength $f_{u}$ was only $13 \%$ higher in the longitudinal direction than in the transverse direction. The key material properties were generally similar in tension and compression, except for ultimate strength in the transverse direction, which was about $50 \%$ higher in compression than tension. 


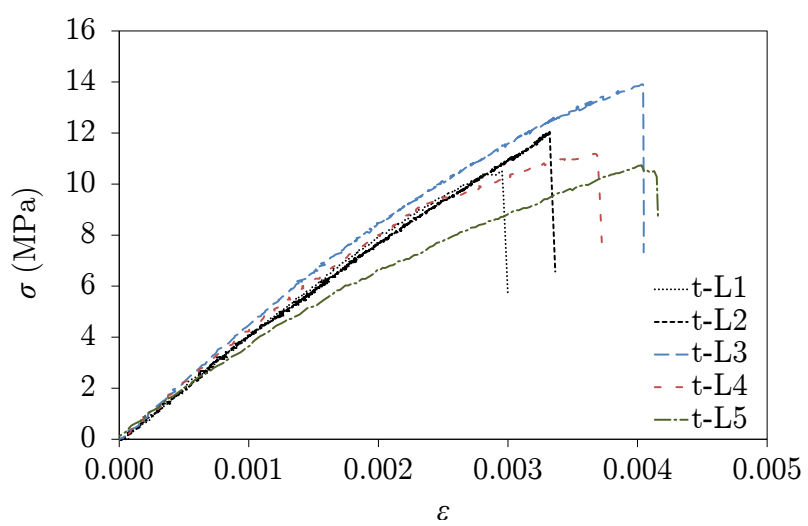

(a) Longitudinal

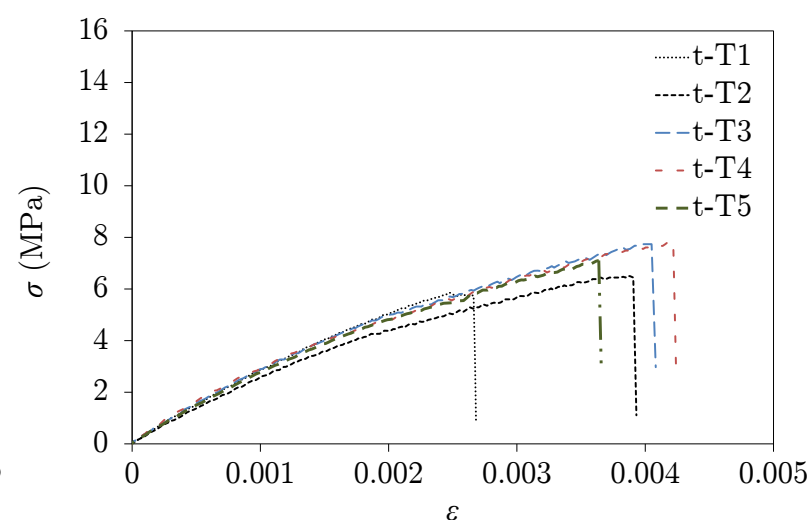

(b) Transverse

Figure 12: Stress-strain curves obtained from OSB tensile coupon tests in (a) the longitudinal and (b) the transverse directions

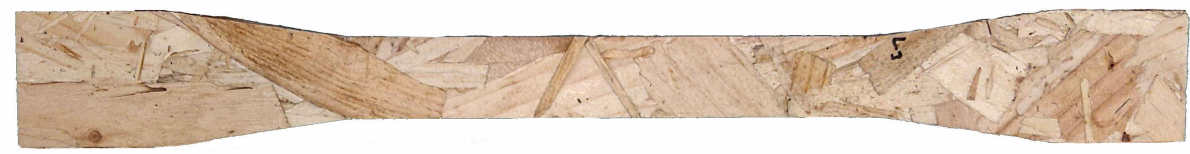

(a) Before test

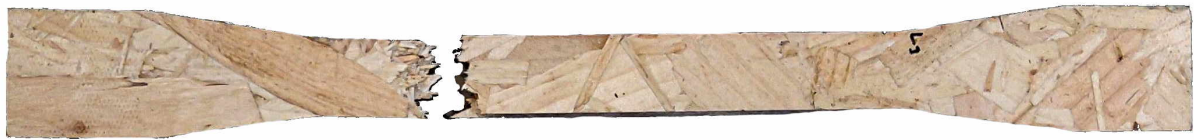

(b) After test

Figure 13: Typical OSB tensile coupon (a) before and (b) after test. 
Table 5: Key measured tensile material properties from OSB tests

\begin{tabular}{ccccc}
\hline Loading direction & Specimen & $E(\mathrm{MPa})$ & $f_{u}(\mathrm{MPa})$ & $\varepsilon_{u}(\%)$ \\
\hline & OSB-t-L1 & 4020 & 10.5 & 0.30 \\
& OSB-t-L2 & 3960 & 12.1 & 0.33 \\
& OSB-t-L3 & 4490 & 13.9 & 0.40 \\
Longitudinal & OSB-t-L4 & 4330 & 11.2 & 0.37 \\
& OSB-t-L5 & 3720 & 10.7 & 0.42 \\
\cline { 2 - 5 } & Average & 4100 & 11.7 & 0.37 \\
& COV & 0.07 & 0.12 & 0.13 \\
\hline \multirow{5}{*}{ Transverse } & OSB-t-T1 & 2980 & 5.86 & 0.26 \\
& OSB-t-T2 & 2650 & 6.51 & 0.39 \\
& OSB-t-T3 & 3040 & 7.74 & 0.41 \\
& OSB-t-T4 & 3200 & 7.85 & 0.42 \\
& OSB-t-T5 & 1800 & 7.11 & 0.37 \\
\cline { 2 - 5 } & Average & 2940 & 7.01 & 0.37 \\
& COV & 0.07 & 0.12 & 0.17 \\
\hline
\end{tabular}

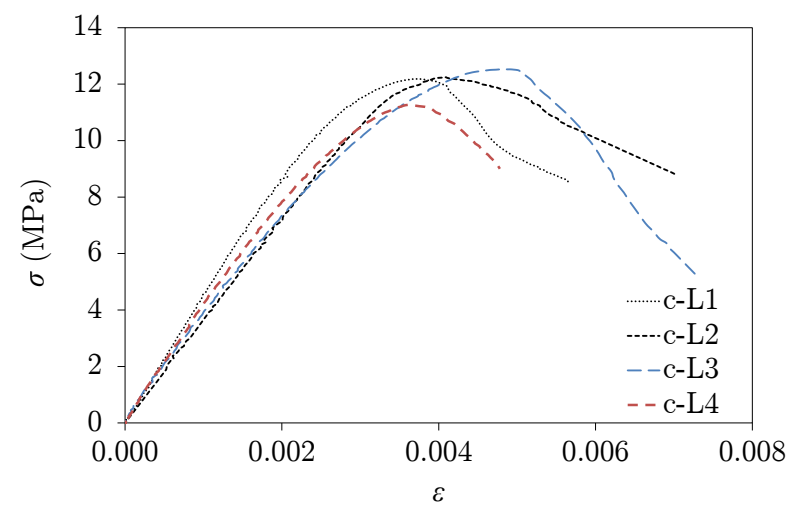

(a) Longitudinal

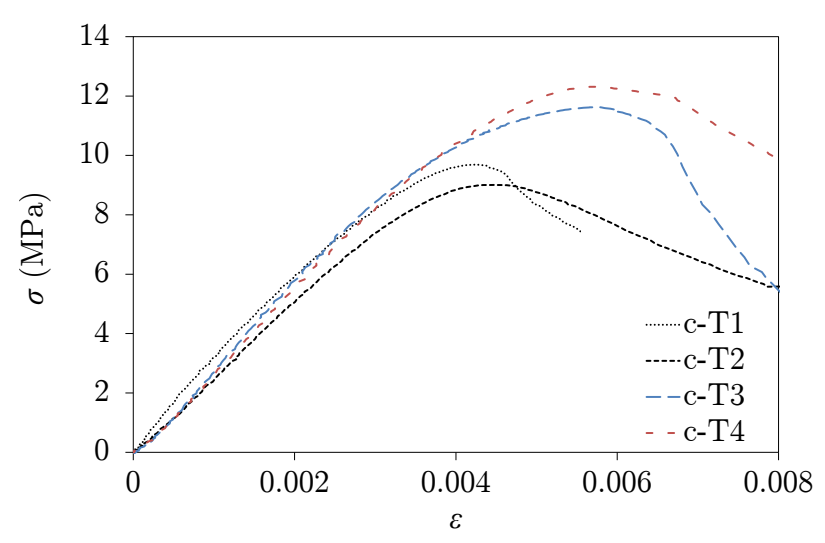

(b) Transverse

Figure 14: Stress-strain curves obtained from OSB compressive coupon tests in (a) the longitudinal and (b) the transverse directions 


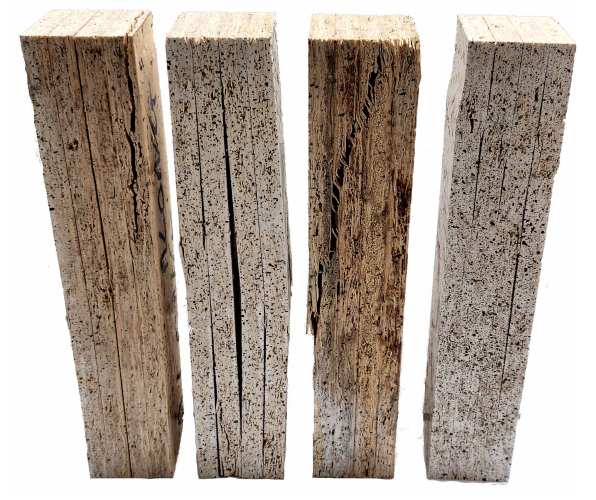

(a) Longitudinal

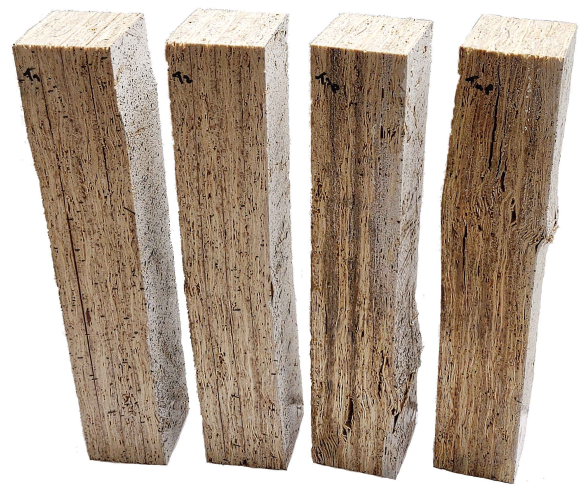

(b) Transverse

Figure 15: Failure modes observed in the OSB compression tests in (a) the longitudinal and (b) the transverse directions

Table 6: Key measured compressive material properties from OSB tests

\begin{tabular}{cccccc}
\hline Loading direction & Specimen & $E(\mathrm{MPa})$ & $f_{u}(\mathrm{MPa})$ & $\varepsilon_{u}(\%)$ & $\varepsilon_{u, 0.8}(\%)$ \\
\hline \multirow{4}{*}{ Longitudinal } & OSB-c-L1 & 4510 & 12.2 & 0.37 & 0.48 \\
& OSB-c-L2 & 3620 & 12.2 & 0.41 & 0.62 \\
& OSB-c-L3 & 3810 & 12.5 & 0.48 & 0.60 \\
& OSB-c-L4 & 4140 & 11.3 & 0.34 & 0.48 \\
\cline { 2 - 6 } & Average & 4020 & 12.1 & 0.40 & 0.54 \\
& COV & 0.10 & 0.05 & 0.15 & 0.14 \\
\hline \multirow{5}{*}{ Transverse } & OSB-c-T1 & 3230 & 9.7 & 0.42 & 0.53 \\
& OSB-c-T2 & 2490 & 9.0 & 0.44 & 0.63 \\
& OSB-c-T3 & 2750 & 11.6 & 0.57 & 0.69 \\
& OSB-c-T4 & 2630 & 12.3 & 0.57 & 0.80 \\
\cline { 2 - 6 } & Average & 2780 & 10.7 & 0.50 & 0.66 \\
& COV & 0.12 & 0.15 & 0.16 & 0.17 \\
\hline
\end{tabular}

\subsection{Screw connectors}

Three different types of screw connectors of $3.5 \mathrm{~mm}, 4.8 \mathrm{~mm}$ and $5.5 \mathrm{~mm}$ diameter were examined in this study and tested in tension and shear. The three types of screws considered 
are illustrated in Figure 16 and the average measured geometric properties are reported in Table 7, where $d$ is the nominal diameter of the screw, $d_{s, t h r}$ is the diameter at the threads, $d_{s, s h}$ is the diameter of the shank excluding the threads, $d_{s, h d}$ is the diameter of the head of the screw, $s_{s, t h r}$ is the pitch between the threads, $h_{s, h d}$ is the depth of the head and $s_{s, n o n t h r}$ is the non-threaded length of the shank below the head of the screw and before the start of the threads.

The $3.5 \mathrm{~mm}$ diameter screws had a bugle head and sharp tip and can be self-driven into up to $2.2 \mathrm{~mm}$ thick steel; these screws are typically used for attaching plasterboard to coldformed steel sections. The $4.8 \mathrm{~mm}$ diameter screws are typically employed for attaching OSB sheathing to cold-formed steel sections while the $5.5 \mathrm{~mm}$ diameter screws were examined to investigate the effect of a larger screw diameter. Both of the $4.8 \mathrm{~mm}$ and $5.5 \mathrm{~mm}$ diameter screws had "wings" just above the screw tip; these were manually removed to allow a direct comparison with the screws of $3.5 \mathrm{~mm}$ diameter.

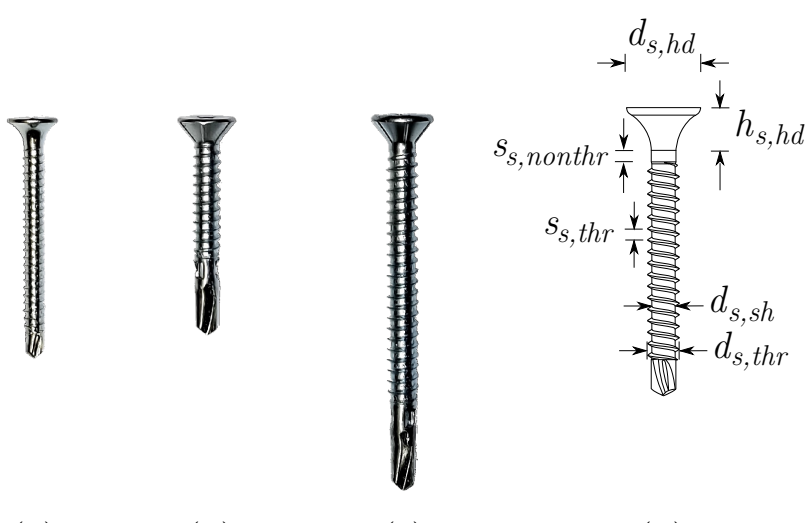

(a)

(b)

(c)

$(\mathrm{d})$

Figure 16: Types of screws considered (a) $3.5 \mathrm{~mm}$ (b) $4.8 \mathrm{~mm}$ and (c) $5.5 \mathrm{~mm}$ in diameter

Table 7: Average measured dimensions of screw connectors

\begin{tabular}{c|cccccc}
\hline$d(\mathrm{~mm})$ & $d_{s, t h r}(\mathrm{~mm})$ & $d_{s, s h}(\mathrm{~mm})$ & $d_{s, h d}(\mathrm{~mm})$ & $s_{s, t h r}(\mathrm{~mm})$ & $h_{s, h d}(\mathrm{~mm})$ & $s_{s, \text { nonthr }}(\mathrm{mm})$ \\
\hline 3.5 & 3.51 & 2.63 & 8.36 & 1.15 & 3.33 & 1.67 \\
4.8 & 4.73 & 3.50 & 10.02 & 1.45 & 4.00 & 0.25 \\
5.5 & 5.38 & 4.04 & 10.55 & 1.65 & 4.48 & 1.63 \\
\hline
\end{tabular}




\subsubsection{Tensile and shear tests on screws}

Tensile screw tests were performed using an $150 \mathrm{kN}$ Instron 5984 hydraulic testing machine; the screws were held in the specifically designed jig shown in Figure 17. Within the jig, the bugle head screw was free to rotate in part 1 and screwed into part 2 - see Figure 17. The force $F$ was applied under displacement control at a constant rate of $0.25 \mathrm{~mm} / \mathrm{min}$, while data were collected using the Bluehill data acquisition system at one second intervals.

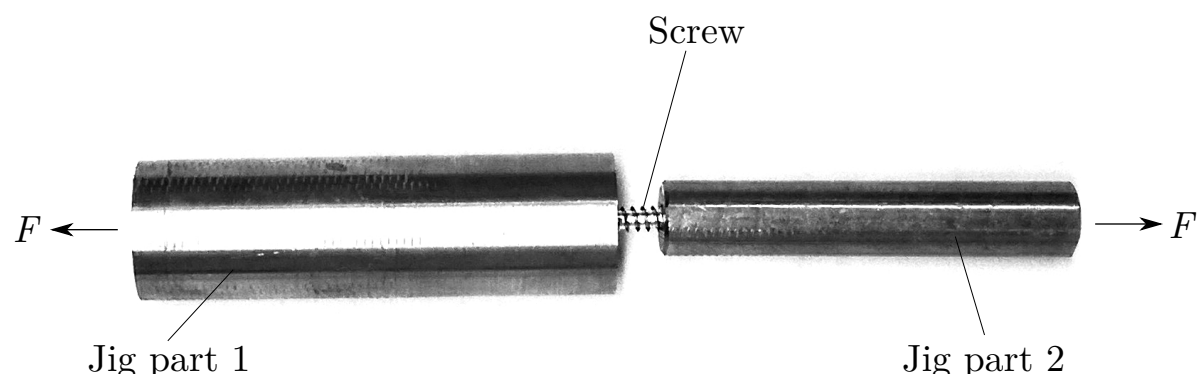

Figure 17: Jig for tensile testing of screw connectors

Double shear screw tests were performed using an $150 \mathrm{kN}$ Instron 5984 testing machine by means of the setup shown in Figure 18 , where tension was maintained throughout testing to avoid any movement/slippage of the screw during loading. The force $F$ at each shear plane was applied using displacement control at a constant rate of $0.25 \mathrm{~mm} / \mathrm{min}$; the Bluehill data acquisition system was employed to collect data at one second intervals.

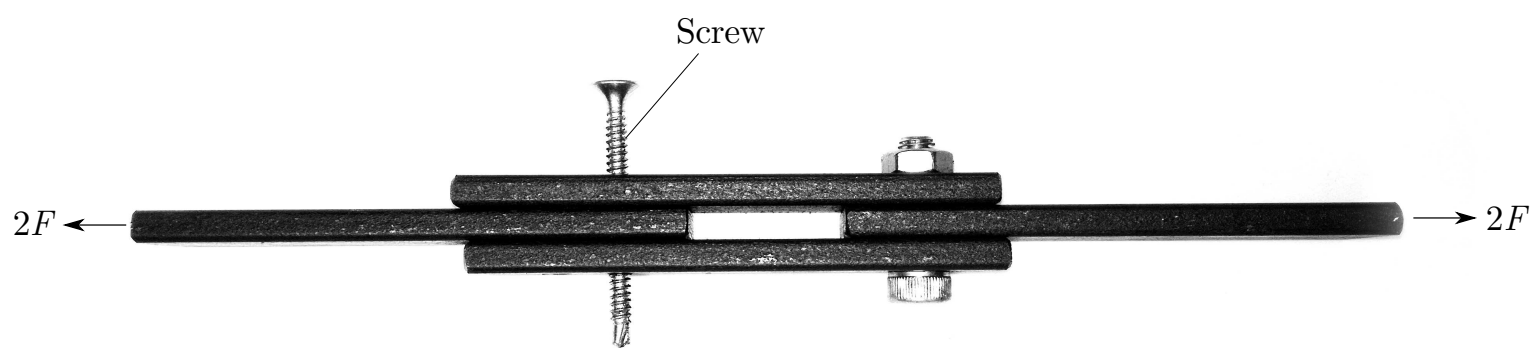

Figure 18: Test setup for double-shear tests on screw connectors, applying force $F$ at each shear plane

\subsubsection{Results of tensile and shear tests on screws}

Three tensile tests and three double shear tests were performed for each of the three different screws; the results are summarised in Tables 8 and 9 respectively, where $F_{u, s}$ is the 
ultimate tensile resistance and $F_{u, v}$ is the ultimate shear resistance. The ultimate tensile stresses $f_{u, s}$ can be calculated using Equation 1

$$
f_{u, s}=\frac{F_{u, s}}{\pi\left(d_{s, s h}^{2} / 4\right)}
$$

Table 8: Results of tensile tests on screws

\begin{tabular}{rccc}
\hline & \multicolumn{3}{c}{$F_{u, s}(\mathrm{kN})$} \\
Test number three screw diameters: & $3.5 \mathrm{~mm}$ & $4.8 \mathrm{~mm}$ & $5.5 \mathrm{~mm}$ \\
\hline Test 1 & 5.92 & 9.72 & 10.19 \\
Test 2 & 6.36 & 8.90 & 11.09 \\
Test 3 & 6.08 & 8.86 & 11.20 \\
\hline Average & 6.12 & 9.16 & 10.83 \\
COV & 0.04 & 0.05 & 0.05 \\
\hline
\end{tabular}

Table 9: Results of shear tests on screws

\begin{tabular}{rccc}
\hline & \multicolumn{3}{c}{$F_{u, v}(\mathrm{kN})$} \\
Test number three screw diameters: & $3.5 \mathrm{~mm}$ & $4.8 \mathrm{~mm}$ & $5.5 \mathrm{~mm}$ \\
\hline Test 1 & 3.64 & 5.12 & 6.45 \\
Test 2 & 3.37 & 4.95 & 5.95 \\
Test 3 & 3.49 & 5.38 & 5.99 \\
\hline Average & 3.50 & 5.15 & 6.13 \\
COV & 0.04 & 0.04 & 0.05 \\
\hline
\end{tabular}

The experimental ultimate shear resistances $F_{u, v}$ reported in Table 9 were found to be within $3 \%$ of the shear resistance values calculated from Equation 2 using the measured ultimate tensile stresses $f_{u, s}$ and screw shank diameters $d_{s, s h}$.

$$
F_{u, v}=\pi \frac{d_{s, s h}^{2}}{4} \frac{f_{u, s}}{\sqrt{3}}
$$




\section{Pull-through behaviour of screws connecting sheathing to cold-formed steel}

Although pull-through tests have featured in some studies [2, 27], this failure mode in isolation has not been extensively investigated in the literature. Hence, a series of pullthrough tests are presented herein. The resistance of the examined connectors depends on the combined effect of the connector head bearing into the surface of the board and the screw threads interacting with the board material.

In total, 25 pull-through tests, covering five different cases, were carried out; the relevant details are given in Table 10. The specimen identification system starts with the letters PT, followed by the nominal diameter of the screw connector $(\times 10)$ in $\mathrm{mm}$, then the number of layers of board and finally a letter corresponding to the board type (with $\mathrm{P}$ for plasterboard and $\mathrm{O}$ for $\mathrm{OSB}$ ). It should be mentioned that the use of double layer plasterboards is common practice to provide increased fire resistance.

Table 10: Details of pull-through test specimens

\begin{tabular}{cccccc}
\hline Designation & $\begin{array}{c}\text { Screw diameter } \\
(\mathrm{mm})\end{array}$ & No. of boards & $\begin{array}{c}\text { Individual layer thickness } \\
(\mathrm{mm})\end{array}$ & Board material & No. of tests \\
\hline PT-35-1P & 3.5 & 1 & 12.5 & Plasterboard & 5 \\
PT-35-2P & 3.5 & 2 & 12.5 & Plasterboard & 5 \\
PT-55-1P & 5.5 & 1 & 12.5 & Plasterboard & 5 \\
PT-55-2P & 5.5 & 2 & 12.5 & Plasterboard & 5 \\
PT-48-1O & 4.8 & 1 & 11.0 & OSB & 5 \\
\hline
\end{tabular}

\subsection{Pull-through tests}

Pull-through testing specifications for timber based materials, such as OSB, and plasterboard, are provided in EN 1383 [35] and EN 14566 [36] respectively. Although both procedures are similar, for consistency, testing was performed in accordance with the provisions of EN 1383 for all tests, using the setup shown in Figures 19 and 20. The board specimens were cut in squares of $100 \times 100 \mathrm{~mm}$. Each screw was driven vertically through the middle of the board (or two boards) with its head finishing flush to the board surface 
- see Figure 19. The screws were then pulled through the board via a circular hole of 60

$\mathrm{mm}$ diameter at the base of a steel box by means of a screw clamp and loading clamp, as shown in Figure 20, Load was applied in displacement control at a constant rate of 0.25 mm/min using an $150 \mathrm{kN}$ Instron 5984 testing machine. Data were acquired using the Bluehill software system at one second intervals.

To capture the net embedment $\delta_{p t}$ of the screw into the board, two measurements of displacement were taken: the vertical deflection of the board adjacent to the screw and the vertical displacement of the screw itself - see Figure 20(b). The net embedment of the screw $\delta_{p t}$, as indicated in Figure 19, was determined by subtracting the deflection of the board from that of the screw. The load-displacement curves from the two LVDTs for a typical case are shown in Figure 21 (a), while the corresponding calculated embedment of the screw $\delta_{p t}$, is shown in Figure 21 (b). The results for all tests are presented in the following section.

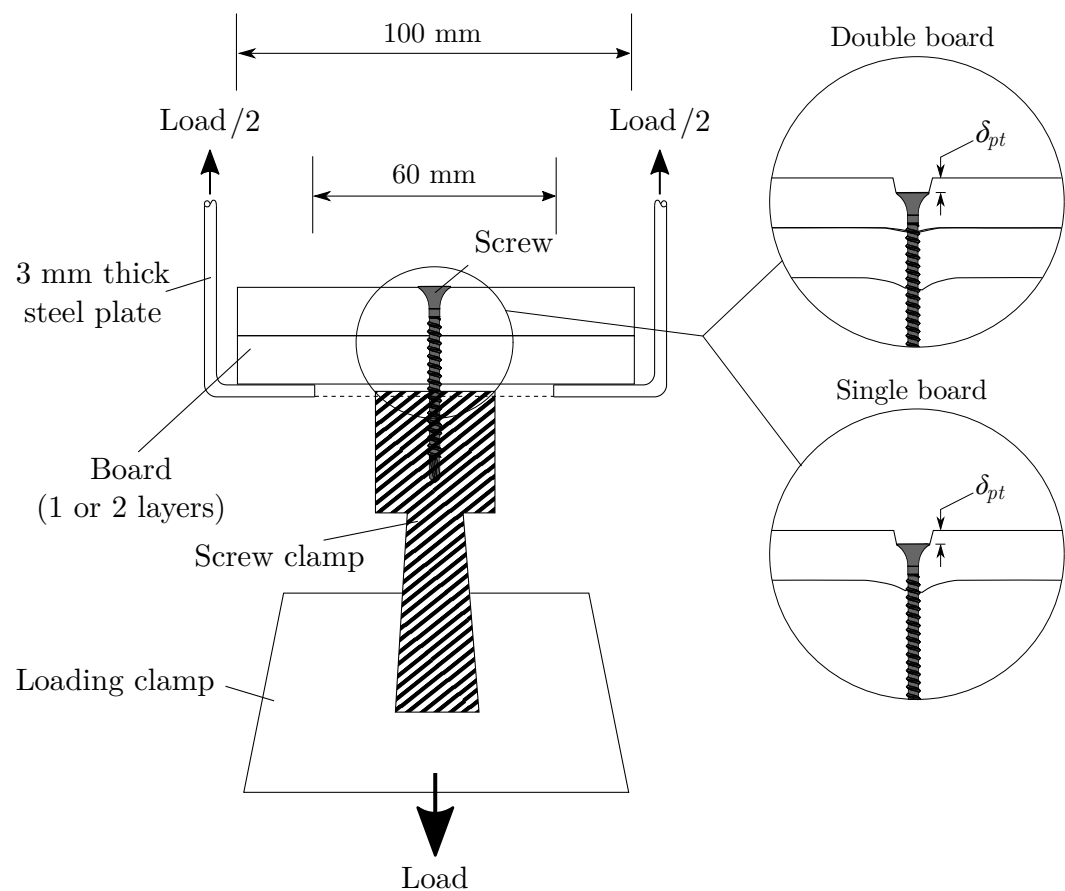

Figure 19: Schematic illustration of pull-through test arrangement 


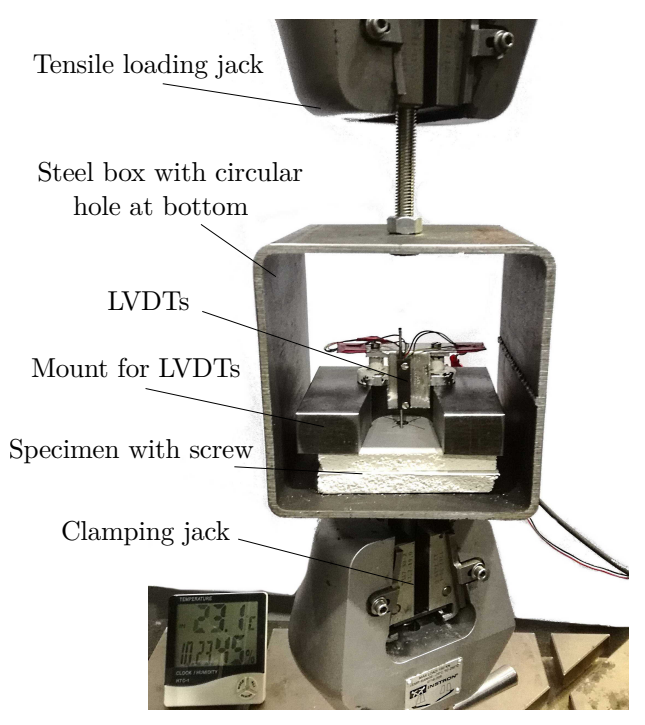

(a)

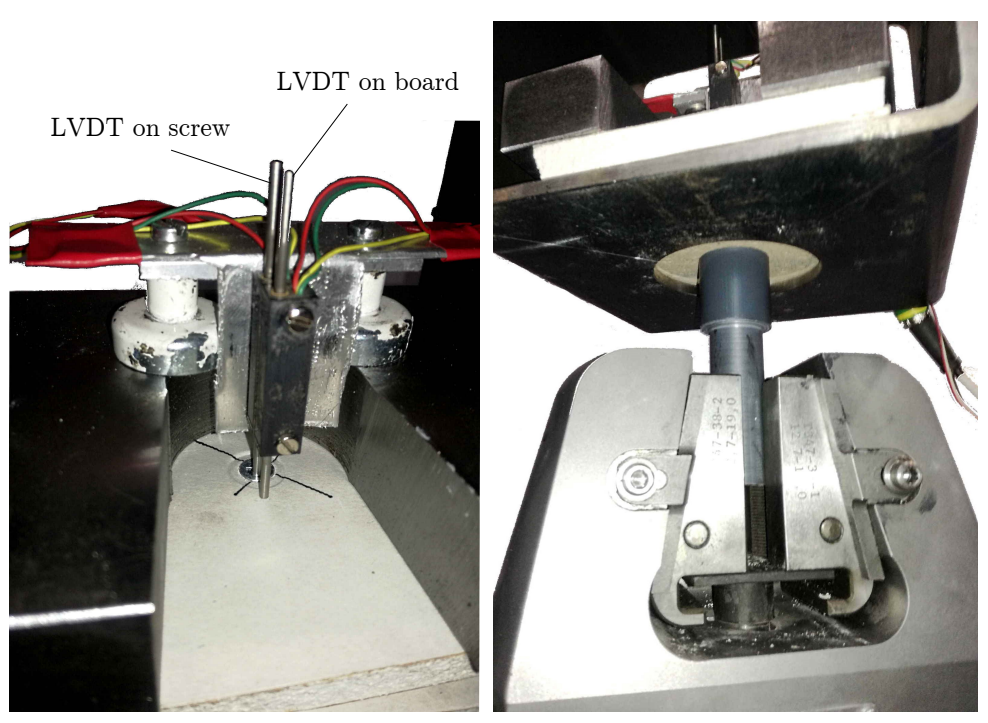

(b)

(c)

Figure 20: Pull-through test setup: (a) overall arrangement, (b) employed instrumentation and (c) bottom view

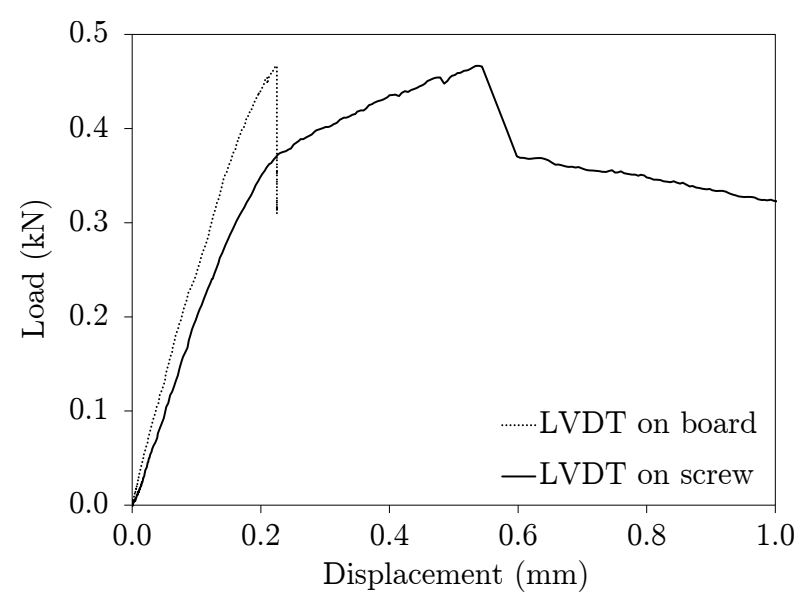

(a)

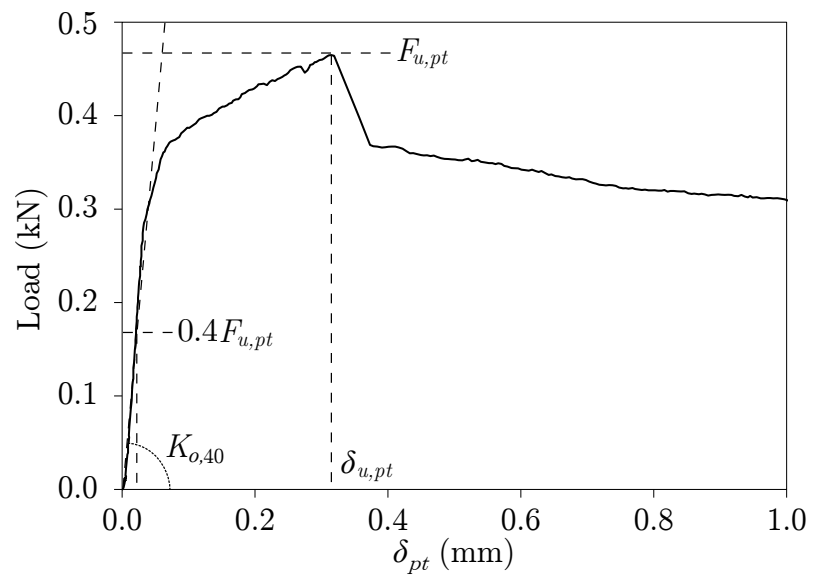

(b)

Figure 21: Load-displacement curves from pull-through tests (a) from two LVDTs (one on screw and one on adjacent board) and (b) showing the net embedment $\delta_{p t}$ and key properties, where $F_{u, p t}$ is the ultimate pull-through resistance, $\delta_{u, p t}$ is the corresponding displacement and $K_{o, 40}$ is the secant stiffness at $0.4 F_{u, p t}$

\subsection{Results of pull-through tests}

For all specimens, testing was continued until failure was clearly marked by a substantial drop in load. For the plasterboard specimens, failure occurred suddenly in the manner 
shown in Figure 22. The OSB specimens exhibited a more gradual decrease in load post mid-depth of the first board.

The OSB pull-through load displacements curves are shown in Figures 23 (c1) and (c2), where a smooth profile can be observed both before and after the peak capacity. This is 
attributed to the screw being pulled through a relatively homogeneous timber-based material, unlike in the plasterboard arrangement where the gypsum core and outer surface paper layers have very different properties.

The key measured properties, as defined in Figure 21 (b), are tabulated for the single and double board specimens in Tables 11 and 12 respectively. These properties include the peak capacity $F_{u, p t}$, the displacement at the peak capacity $\delta_{u, p t}$ and the secant stiffness $K_{o, 40}$, calculated by dividing the load at $40 \%$ of $F_{u, p t}$ by the corresponding displacement, as shown in Figure 21 (b). For the specimens comprising two boards, the peak capacity and corresponding displacement at the second peak are denoted by $F_{u, p t, 2}$ and $\delta_{u, p t, 2}$ respectively. Finally, the post peak properties $F_{u, p t, 0.8}$ and $\delta_{u, p t, 0.8}$ are also provided, where $F_{u, p t, 0.8}$ is the load at $80 \%$ of $F_{u, p t}$ and $\delta_{u, p t, 0.8}$ is the corresponding displacement. For the tests with the 5.5 $\mathrm{mm}$ screws and two boards, since the load did not decrease as low as $F_{u, p t, 0.8}$ between $F_{u, p t}$ and $F_{u, p t, 2}, F_{u, p t, 0.8}$ was taken as the lowest point between the two peaks and $\delta_{u, p t, 0.8}$ as the corresponding measured displacement. A summary of the average measured key properties is provided by Table 13 .

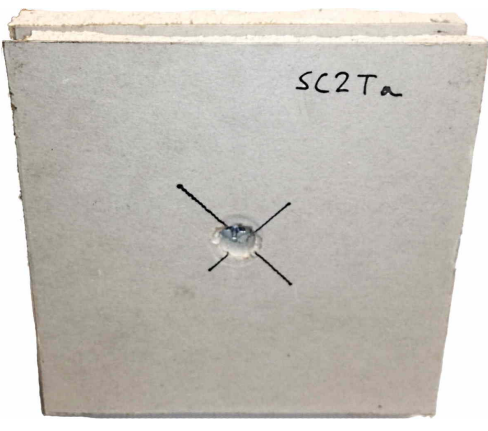

(a)

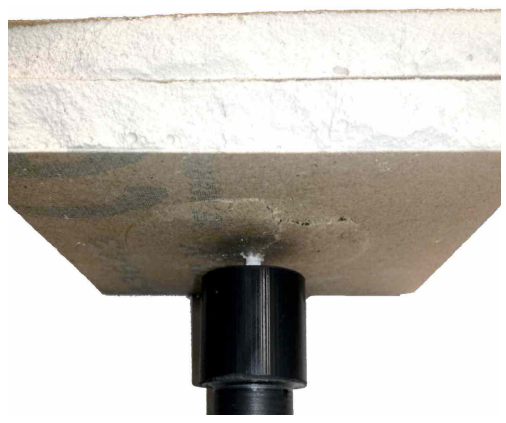

(b)

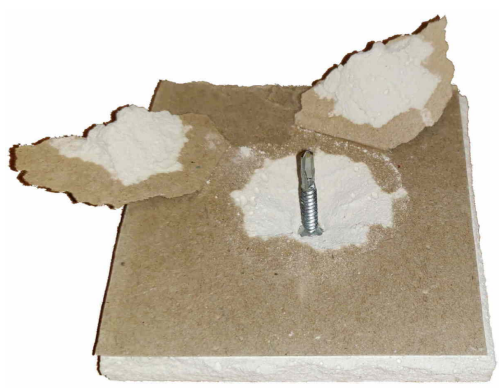

(c)

Figure 22: Failure of plasterboard pull-through specimens: (a) top view, embedded screw (b) bottom view of board failing (c) rupture of the underside of plasterboard forming a conical surface 


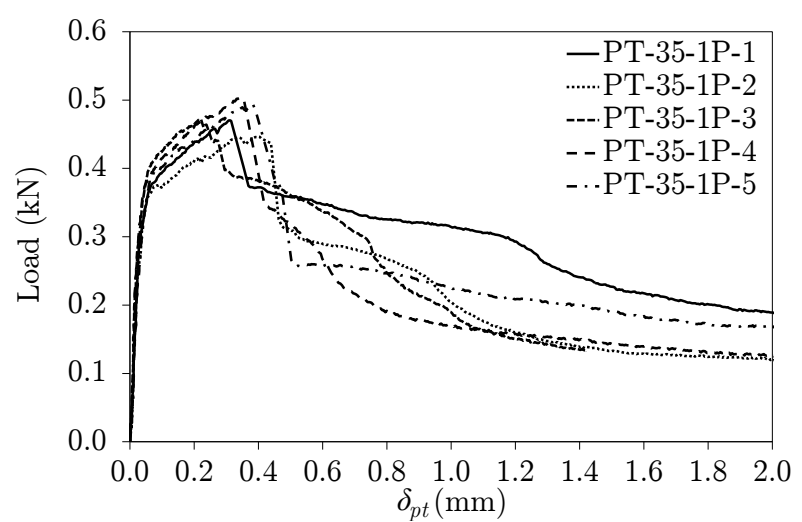

(a1)

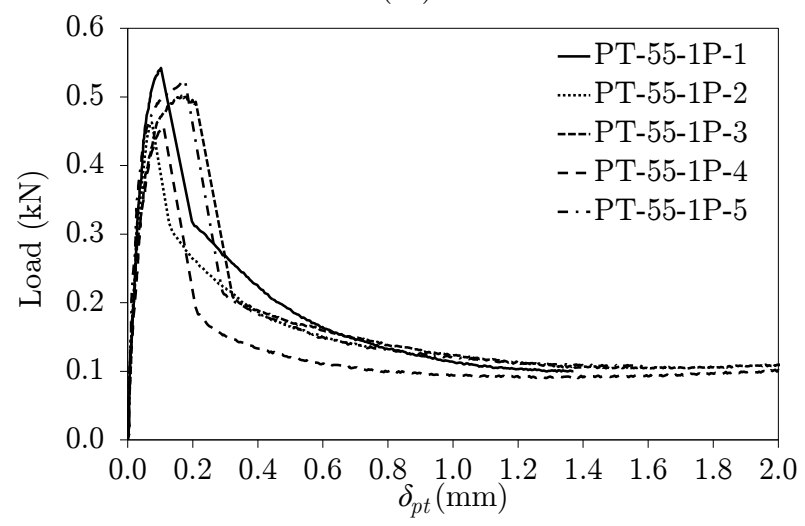

(b1)

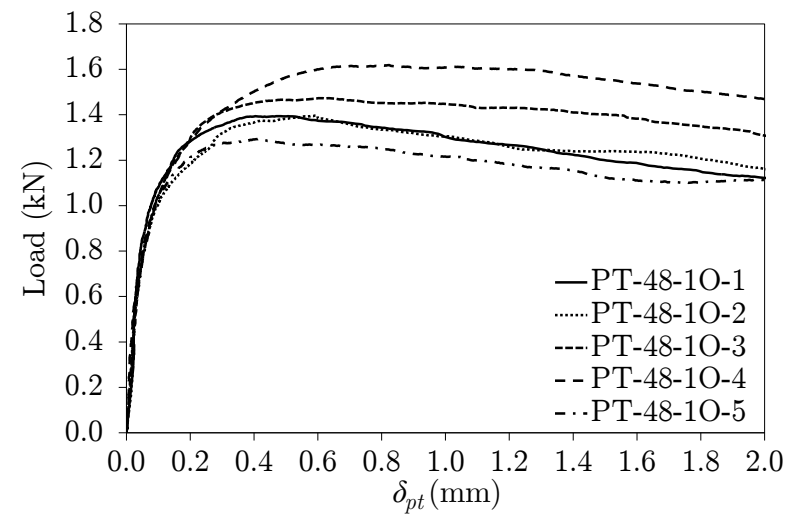

(c1)

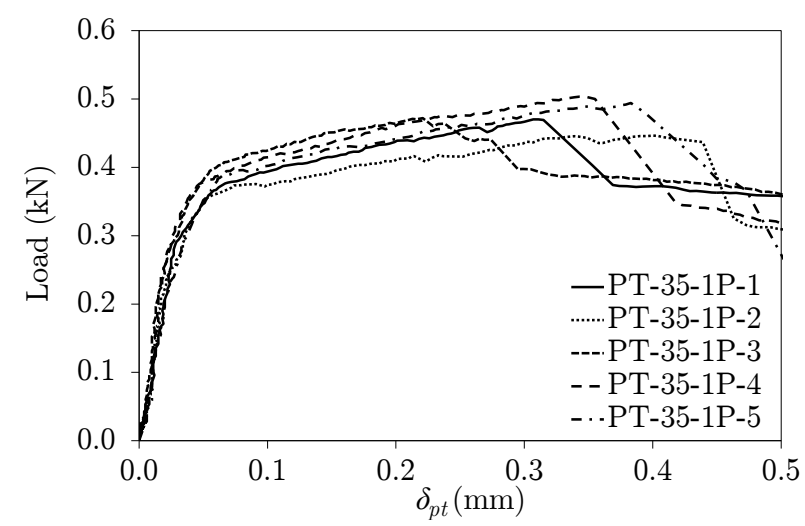

(a2)

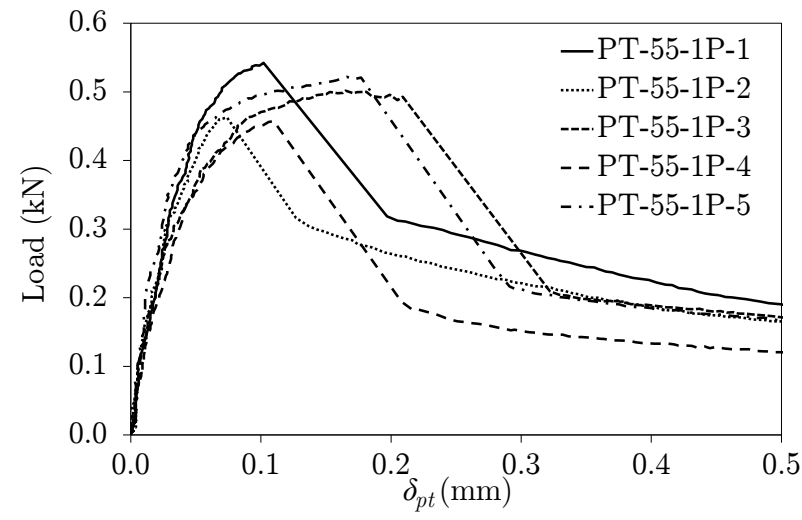

(b2)

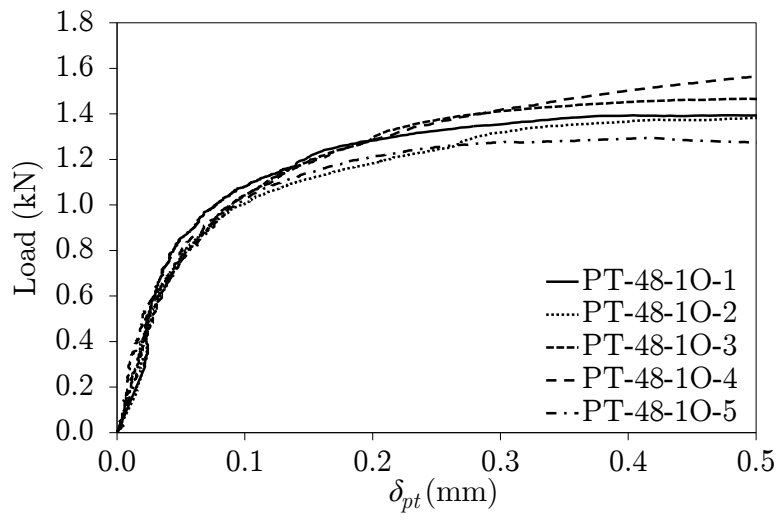

(c2)

Figure 23: Single board pull-through load-displacement curves for (a) PT-35-1P, (b) PT-55-1P and (c) PT-48-1O on a horizontal scale up to $2 \mathrm{~mm}$ (a1, b1, c1) and up to $0.5 \mathrm{~mm}(\mathrm{a} 2, \mathrm{~b} 2, \mathrm{c} 2)$ 

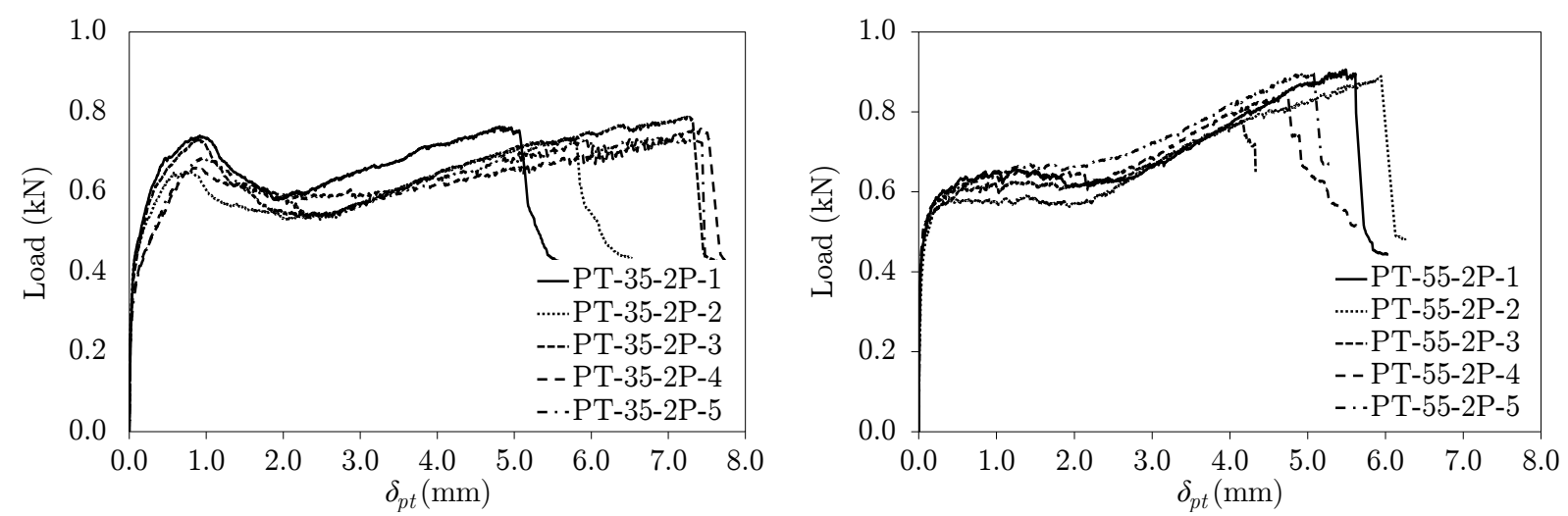

(a1)

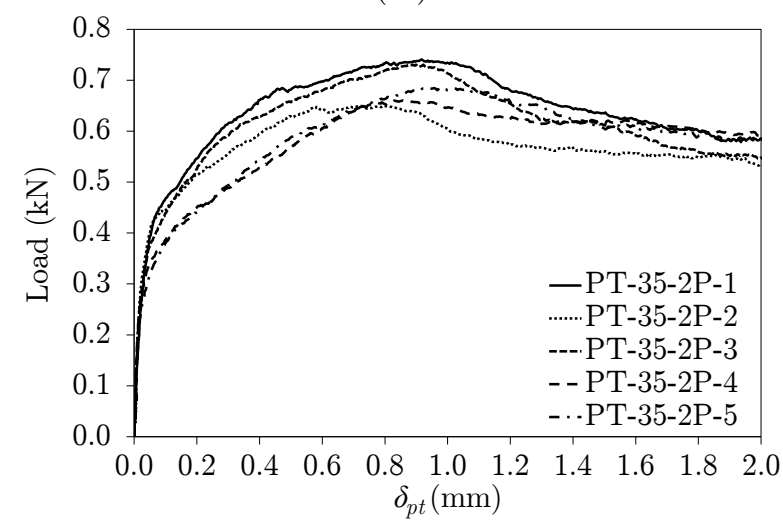

(b1)

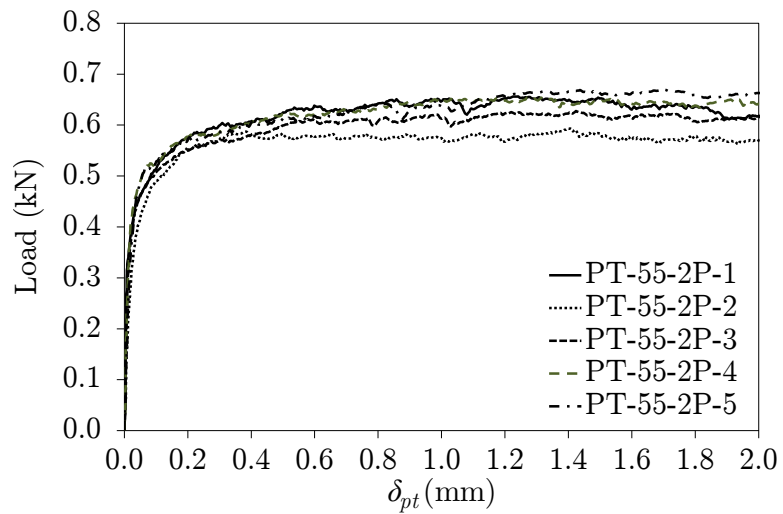

(a2)

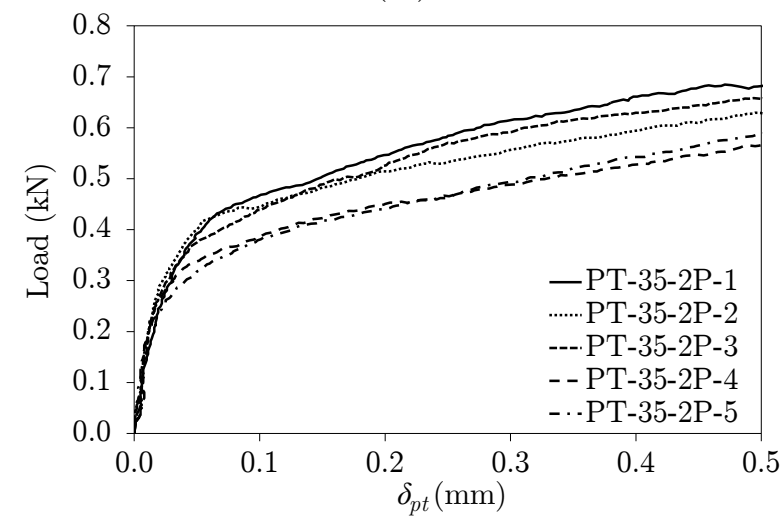

(a3)

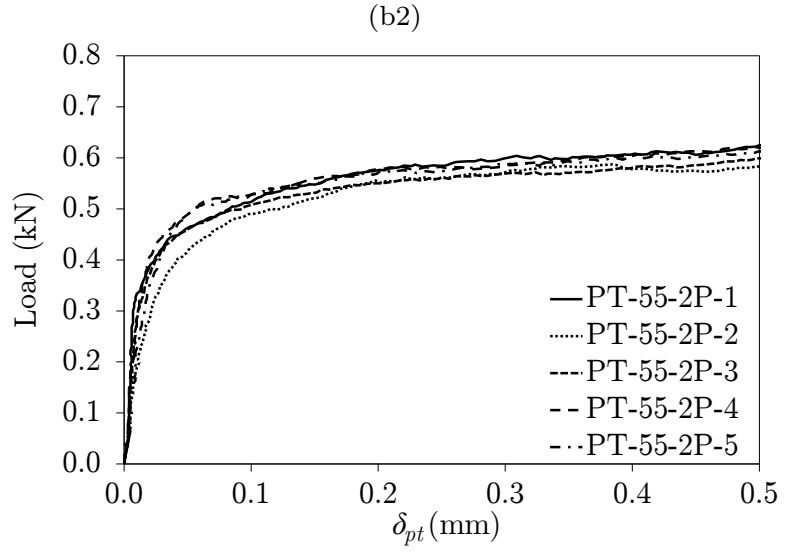

(b3)

Figure 24: Two layer board pull-through load-displacement curves for (a) PT-35-2P and (b) PT-55-2P on a horizontal scale up to $8 \mathrm{~mm}$ (a1, b1), up to $2 \mathrm{~mm}$ (a2, b2) and up to $0.5 \mathrm{~mm}$ (a3, b3) 
Table 11: Experimental results from pull-through tests with single boards

\begin{tabular}{lccccc}
\hline Designation & $K_{o, 40}(\mathrm{kN} / \mathrm{mm})$ & $F_{u, p t}(\mathrm{kN})$ & $\delta_{u, p t}(\mathrm{~mm})$ & $F_{u, p t, 0.8}(\mathrm{kN})$ & $\delta_{u, p t, 0.8}(\mathrm{~mm})$ \\
\hline PT-35-1P-1 & 9.49 & 0.47 & 0.31 & 0.38 & 0.37 \\
PT-35-1P-2 & 10.0 & 0.45 & 0.40 & 0.36 & 0.44 \\
PT-35-1P-3 & 12.6 & 0.47 & 0.22 & 0.38 & 0.43 \\
PT-35-1P-4 & 11.0 & 0.50 & 0.34 & 0.40 & 0.37 \\
PT-35-1P-5 & 9.26 & 0.49 & 0.38 & 0.40 & 0.44 \\
Average & 10.5 & 0.48 & 0.33 & 0.38 & 0.41 \\
COV & 0.13 & 0.05 & 0.21 & 0.05 & 0.09 \\
\hline PT-55-1P-1 & 13.4 & 0.54 & 0.10 & 0.43 & 0.16 \\
PT-55-1P-2 & 15.8 & 0.46 & 0.07 & 0.37 & 0.11 \\
PT-55-1P-3 & 11.9 & 0.50 & 0.17 & 0.40 & 0.24 \\
PT-55-1P-4 & 13.3 & 0.46 & 0.11 & 0.37 & 0.16 \\
PT-55-1P-5 & 16.9 & 0.52 & 0.17 & 0.42 & 0.22 \\
Average & 14.2 & 0.50 & 0.12 & 0.40 & 0.18 \\
COV & 0.14 & 0.07 & 0.33 & 0.07 & 0.29 \\
\hline PT-48-1O-1 & 17.9 & 1.39 & 0.42 & 1.12 & 2.08 \\
PT-48-1O-2 & 17.5 & 1.40 & 0.56 & 1.12 & 2.32 \\
PT-48-1O-3 & 18.8 & 1.47 & 0.55 & 1.18 & 2.42 \\
PT-48-1O-4 & 19.4 & 1.62 & 0.74 & 1.29 & 2.46 \\
PT-48-1O-5 & 18.9 & 1.29 & 0.41 & 1.03 & 2.71 \\
Average & 18.5 & 1.44 & 0.54 & 1.15 & 2.40 \\
COV & 0.04 & 0.08 & 0.25 & 0.08 & 0.10 \\
\hline & & & 0.45 & \\
\hline
\end{tabular}


Table 12: Experimental results from pull-through tests with two layers of board

\begin{tabular}{lccccccc}
\hline Designation & $K_{o, 40}(\mathrm{kN} / \mathrm{mm})$ & $F_{u, p t}(\mathrm{kN})$ & $\delta_{u, p t}(\mathrm{~mm})$ & $F_{u, p t, 0.8}(\mathrm{kN})$ & $\delta_{u, p t, 0.8}(\mathrm{~mm})$ & $F_{u, p t, 2}(\mathrm{kN})$ & $\delta_{u, p t, 2}(\mathrm{~mm})$ \\
\hline PT-35-2P-1 & 14.0 & 0.74 & 0.92 & 0.59 & 1.83 & 0.76 & 4.81 \\
PT-35-2P-2 & 17.7 & 0.65 & 0.80 & 0.52 & 2.05 & 0.74 & 5.77 \\
PT-35-2P-3 & 15.6 & 0.73 & 0.90 & 0.58 & 1.65 & 0.79 & 7.24 \\
PT-35-2P-4 & 17.1 & 0.66 & 0.86 & 0.53 & 2.30 & 0.76 & 7.42 \\
PT-35-2P-5 & 17.9 & 0.69 & 0.98 & 0.55 & 2.29 & 0.74 & 6.90 \\
Average & 16.5 & 0.69 & 0.89 & 0.55 & 2.03 & 0.76 & 6.43 \\
COV & 0.10 & 0.06 & 0.08 & 0.06 & 0.14 & 0.03 & 0.17 \\
\hline PT-55-2P-1 & 31.1 & 0.66 & 1.24 & $0.61^{*}$ & $1.91^{*}$ & 0.91 & 5.43 \\
PT-55-2P-2 & 18.4 & 0.59 & 1.42 & $0.56^{*}$ & $1.94^{*}$ & 0.89 & 5.63 \\
PT-55-2P-3 & 27.6 & 0.63 & 1.42 & $0.61^{*}$ & $1.81^{*}$ & 0.78 & 3.90 \\
PT-55-2P-4 & 29.5 & 0.65 & 1.28 & $0.60^{*}$ & $2.16^{*}$ & 0.85 & 5.09 \\
PT-55-2P-5 & 21.4 & 0.67 & 1.70 & $0.65^{*}$ & $1.84^{*}$ & 0.90 & 4.75 \\
Average & 25.6 & 0.64 & 1.41 & 0.61 & 1.93 & 0.86 & 4.96 \\
COV & 0.21 & 0.05 & 0.13 & 0.05 & 0.07 & 0.06 & 0.14 \\
\hline
\end{tabular}

*Load did not drop to $80 \%$ of $F_{u, p t} ; F_{u, p t, 0.8}$ taken as lowest point between the first and second peaks

Table 13: Average measured results from pull-through tests

\begin{tabular}{cccccccc}
\hline Designation & $K_{o, 40}(\mathrm{kN} / \mathrm{mm})$ & $F_{u, p t}(\mathrm{kN})$ & $\delta_{u, p t}(\mathrm{~mm})$ & $F_{u, p t, 0.8}(\mathrm{kN})$ & $\delta_{u, p t, 0.8}(\mathrm{~mm})$ & $F_{u, p t, 2}(\mathrm{kN})$ & $\delta_{u, p t, 2}(\mathrm{~mm})$ \\
\hline PT-35-1P & 10.5 & 0.48 & 0.33 & 0.38 & 0.41 & - & - \\
PT-35-2P & 16.5 & 0.69 & 0.89 & 0.55 & 2.03 & 0.76 & 6.43 \\
PT-55-1P & 14.2 & 0.50 & 0.12 & 0.40 & 0.18 & - & - \\
PT-55-2P & 25.6 & 0.64 & 1.41 & $0.61^{*}$ & $1.93^{*}$ & 0.86 & 4.96 \\
PT-48-1O & 18.5 & 1.44 & 0.54 & 1.15 & 2.40 & - & - \\
\hline
\end{tabular}

*Load did not drop to $80 \%$ of $F_{u, p t} ; F_{u, p t, 0.8}$ taken as lowest point between the first and second peaks

\section{Shear behaviour of screws connecting sheathing to cold-formed steel}

The principal action resisted by fixings connecting two elements and resisting relative slip between them is shear. Hence, the shear behaviour of an individual connection between two elements (the sheathing and the steel in the present context) is characterised by its loadslip response. A procedure to determine the shear behaviour and strength of a connection 
between plasterboard and timber is provided in EN 520 [30] - see Figure 25 (a). This test procedure was adapted by Fiorino et al. [18] where, instead of timber members, two coldformed steel sections were used, with the plasterboard screwed to the opposite flanges of the cold-formed steel profiles. Similar test setups with plasterboard connected to both sides of cold-formed steel members were employed in [14, 17, 20, 22], while test arrangements with a single board and flat cold-formed steel plates were reported in [21]. According to EN 1994-1-1 [37], push-out tests are the standard means for determining the shear behaviour and capacity of connectors in composite construction - see Figure 25 (b). Therefore, several researchers have adopted this approach to determine the shear behaviour of fasteners connecting coldformed steel sections and various types of boards, including plasterboards [38], timber based boards [5, 39] and cement based boards [23]. The latter approach is considered to be more representative of how a typical stud column is loaded in practice, and is therefore employed herein.

In total, 18 push-out tests were performed with the varied parameters being the screw size, the number of plasterboard layers and the steel thickness in order to investigate their influence on the load-slip behaviour in shear. Details of the six investigated combinations of tests parameters are provided in Table 14, three repeat specimens were tested for each combination. The adopted labelling system for the test specimens begins with the letters PO for push-out tests, followed by the nominal diameter of the screw in mm multiplied by ten, then by $1 \mathrm{P}$ or $2 \mathrm{P}$ for single or double plasterboard layers respectively and finally by the nominal thickness of the steel section in mm multiplied by ten. The key characteristics of the steel, plasterboard and screws are as provided in Section 2. 


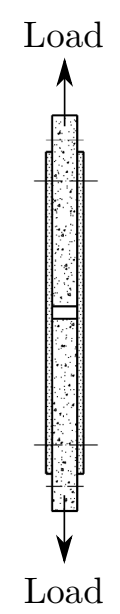

(a)

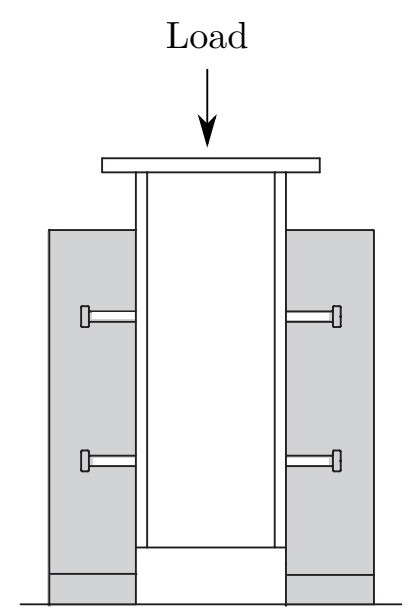

(b)

Figure 25: Standard tests for measuring the shear behaviour of a connector between two elements: (a) pull-test in EN 520 [30] and (b) push-test in Eurocode 4 [37]

Table 14: Combinations of parameters investigated in push-out tests

\begin{tabular}{ccccc}
\hline Designation & Screw diameter $(\mathrm{mm})$ & No. of boards & Steel thickness $(\mathrm{mm})$ & No. of tests \\
\hline PO-35-1P-12 & 3.5 & 1 & 1.2 & 3 \\
PO-35-2P-12 & 3.5 & 2 & 1.2 & 3 \\
PO-35-1P-20 & 3.5 & 1 & 2.0 & 3 \\
PO-35-2P-20 & 3.5 & 2 & 2.0 & 3 \\
PO-55-1P-12 & 5.5 & 1 & 1.2 & 3 \\
PO-55-2P-20 & 5.5 & 2 & 2.0 & 3 \\
\hline
\end{tabular}

\subsection{Push-out tests}

Schematic views of the employed push-out test setup are shown in Figure 26. The test specimens consisted of two back-to-back $400 \mathrm{~mm}$ long cold-formed steel lipped channel sections of $150 \mathrm{~mm}$ depth and $44 \mathrm{~mm}$ width, with square $400 \times 400 \mathrm{~mm}$ boards connected to their flanges. Single or double layers of plasterboard were connected to the steel sections with four screws. 
Loading was applied to the push-out specimens by a $750 \mathrm{kN}$ Instron hydraulic testing machine in the arrangement shown in Figures 26 and 27. The specimens were loaded under displacement control at a constant displacement rate of $0.25 \mathrm{~mm} / \mathrm{min}$. The slip $\delta_{\text {po }}$ between the steel section and the boards, illustrated in Figure 26, was measured using four LVDTs, as shown in Figure 28 (b); the LVDTs were mounted on the steel section and recorded the slip between steel and the inside surface of the boards, as shown in Figure 27, to eliminate any additional displacement from the potential crushing of the plasterboard edges under the compression load.

Load and slip were recorded at one second intervals using the DATASCAN acquisition system. Load-slip measurements were reported after averaging the four LVDT displacement readings and after dividing the force recorded from the hydraulic actuator by eight to calculate the load per screw. 


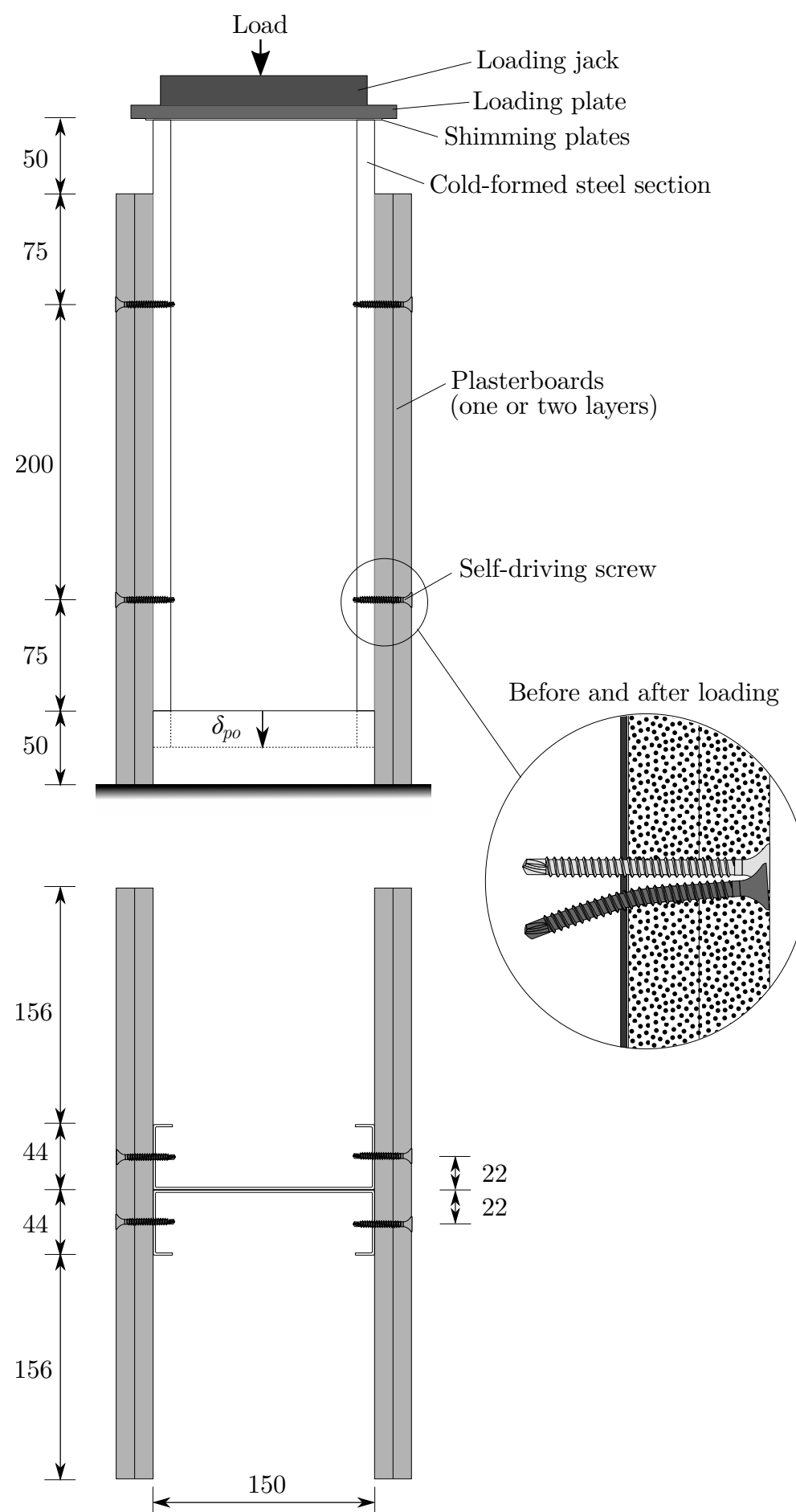

Figure 26: Schematic views of push-out test arrangement in elevation and from above. All dimensions are given in $\mathrm{mm}$. 


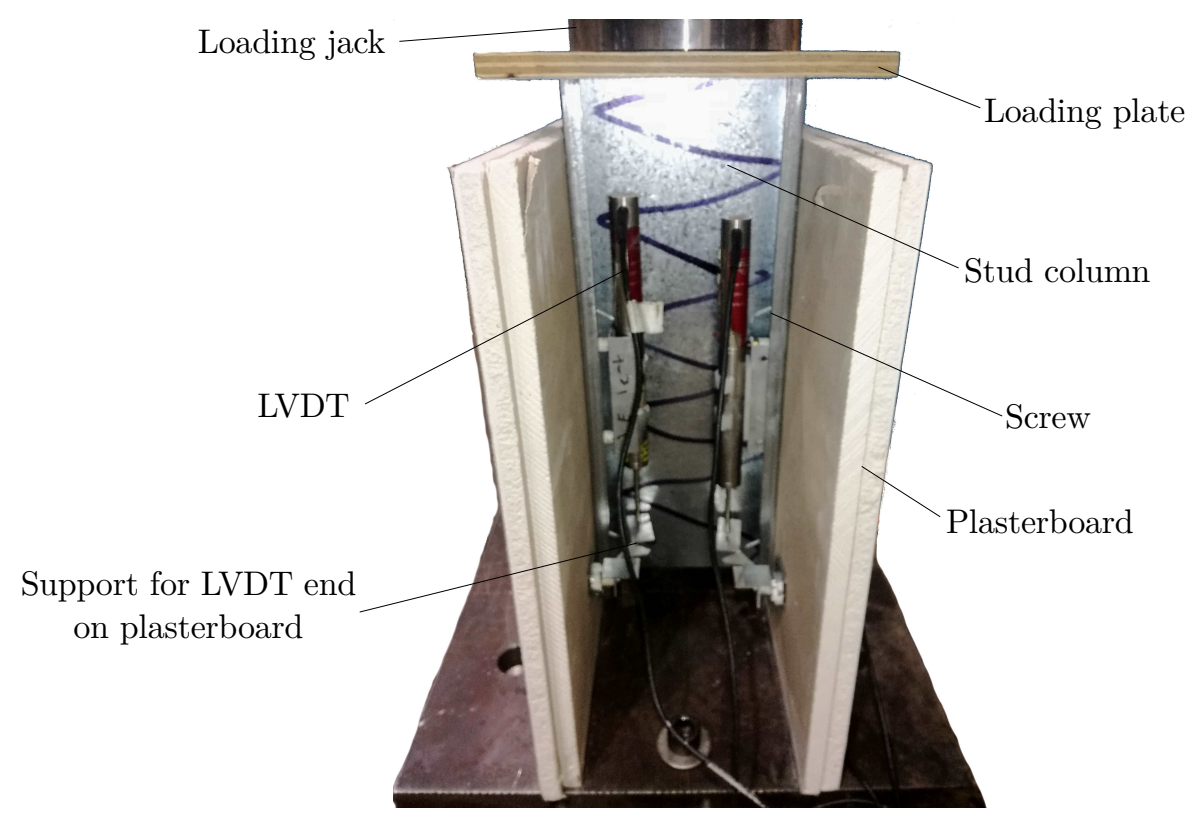

Figure 27: Experimental arrangement for push-out tests

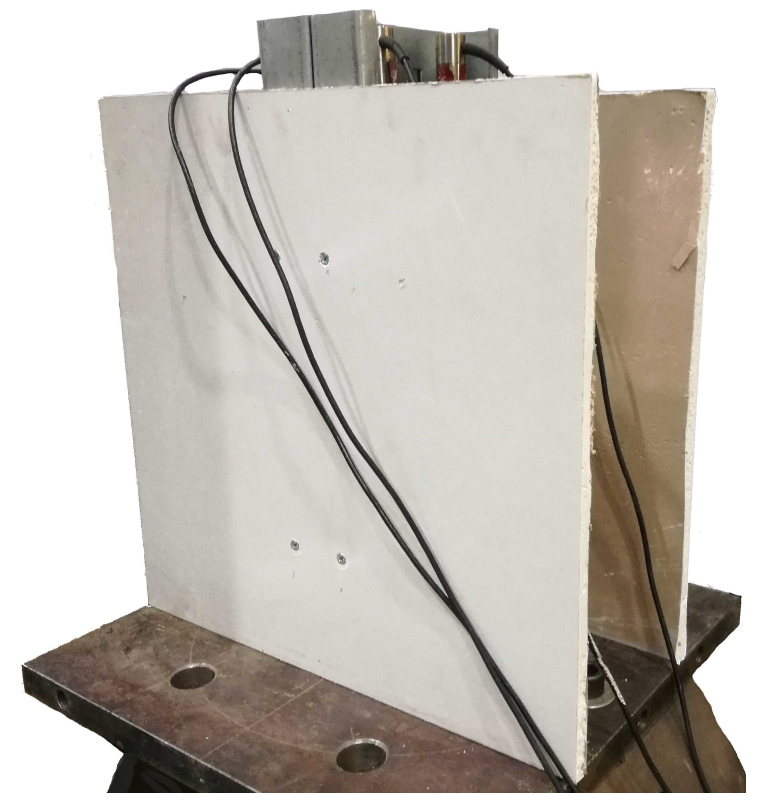

(a)

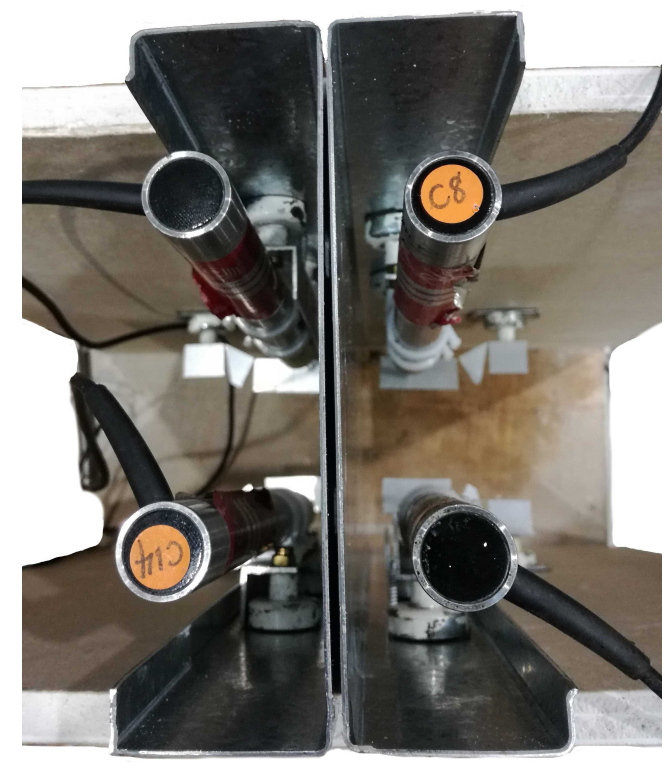

(b)

Figure 28: (a) Overview and (b) top view of push-out test specimens 


\subsection{Results of push-out tests}

All tests were carried out until failure or until the recorded slip exceeded three times the diameter of the screw fixing. Typical failure modes are shown in Figure 30. For the single board arrangements, the main failure mode observed was bearing of the screw into the board and tilting of the screw. For the double board arrangements, the failure modes also featured bearing and tilting, but this was accompanied in some cases by pull-through and screw bending; screw shear failure occurred for the specimens featuring the smaller diameter $(3.5 \mathrm{~mm})$ screws in the thicker steel section $(2 \mathrm{~mm})$. On the back surface of the plasterboards, the weaker paper was torn as the screw tilted downwards, as shown in Figure 30 (c).

The measured load-slip $\left(\delta_{p o}\right)$ responses per connector are given in Figure 31 for the single board specimens and in Figure 32 for the double board specimens. For each set of tests, two graphs are given - one up to a slip of $16 \mathrm{~mm}$, to show the overall response to the end of the test and a second up to a slip of $2 \mathrm{~mm}$ to enable the initial part of the load-slip profile to be seen more clearly. As expected, the shape of the load-slip response for all specimens with one layer of plasterboard is consistent since all the screws failed in a similar manner by tilting and bearing into the plasterboard. Higher capacities were achieved with the use of the $5.5 \mathrm{~mm}$ screws, compared to the conventional $3.5 \mathrm{~mm}$ ones, which is expected due to the larger contact area between the screw and the board.

The key measured properties from the push-out tests are tabulated for the single and double layer board specimens in Tables 15 and 16 respectively, where $F_{u, p o}$ is the ultimate shear capacity per screw, $\delta_{u, p o}$ is the displacement at the ultimate capacity, $K_{o}$ is the initial stiffness calculated using Equation (3) and $K_{o, 40}$ is the secant stiffness measured at $40 \%$ of $F_{u, p o}$.

$$
K_{o}=\frac{1}{n}\left(\sum_{i=1}^{n} K_{o, i}\right) \quad \text { while } \quad K_{o, n} \geq 0.75 K_{o, 1}
$$

$K_{o}$ is the the average value of the secant stiffnesses calculated between the points at $0.1 F_{u, p o}$ and either $0.4 F_{u, p o}$ or up to the point where the calculated stiffness is no less than $75 \%$ of the stiffness calculated at $0.1 F_{u, p o}$ (with $K_{o, i}$ being the secant stiffness corresponding to 
point $i$ ). The $K_{o, 40}$ stiffness is typically reported in the literature [17, 18] and therefore represents a useful reference value, while $K_{o}$ provides a more accurate representation of the initial stiffness, particularly when there is high degree of nonlinearity in the early stages of the load-slip response. Calculation of $F_{u, p o}, \delta_{u, p o}$ and $K_{o}$ for typical load-slip curves per connector in shear are illustrated in Figure 29.
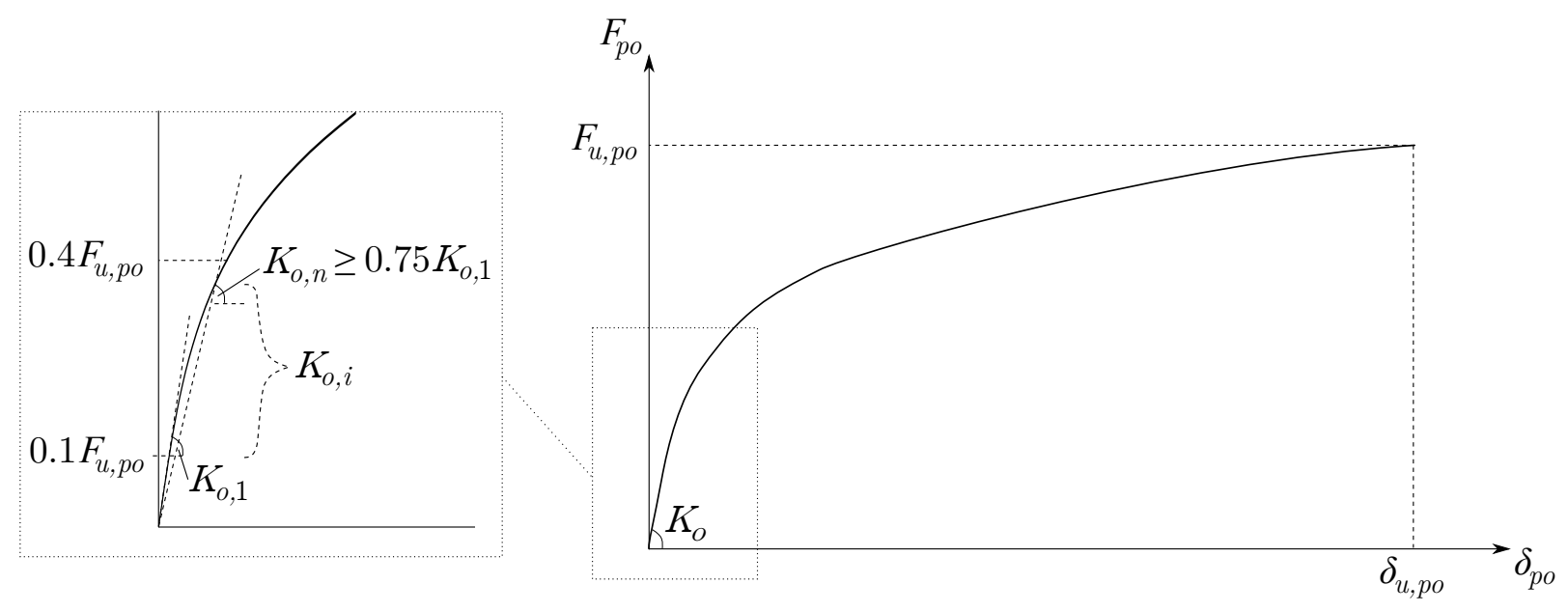

Figure 29: Typical load-slip curve per connector in shear and calculation detail for the initial stiffness $K_{o}$

A summary of the average measured properties from the push-out tests, along with the observed failure modes, is provided in Table 17. The failure modes are also illustrated in Figure 33. A combined failure mode is indicated by the + sign while progress to additional modes is indicated by the $\rightarrow$ sign. Higher capacities are observed when two boards are used, while thicker steel reduced tilting and increased bearing along the whole length of the screw in contact with board resulting in higher initial stiffness. A $180 \%$ increase in $F_{u, p o}$ was achieved by increasing the diameter of the screw from $3.5 \mathrm{~mm}$ to $5.5 \mathrm{~mm}$, increasing the number of layers of plasterboard from one to two and thickening the cold-formed steel section from $1.2 \mathrm{~mm}$ to $2.0 \mathrm{~mm}$. It is important to note that the $5.5 \mathrm{~mm}$ screws are not designed for use with plasterboards and therefore, their head shape is not ideal; a flatter head would have led to further improvements in performance, as demonstrated with the pull-through tests in Section 3. 


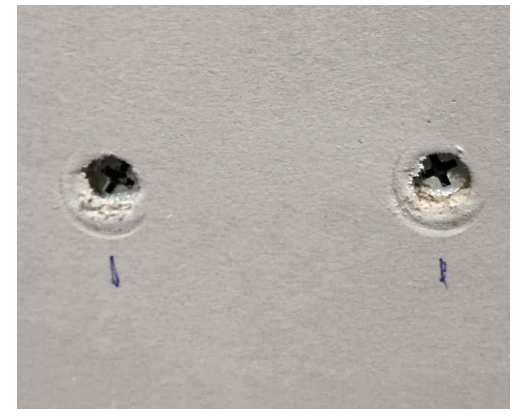

(a)

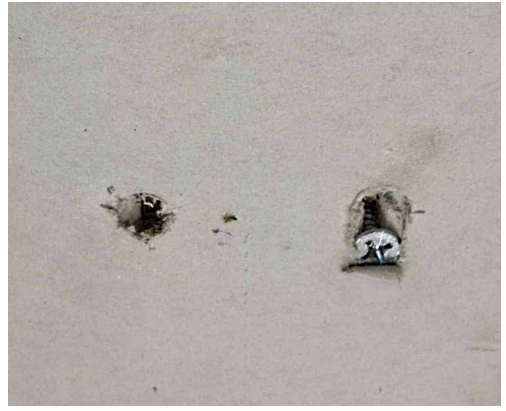

(b)

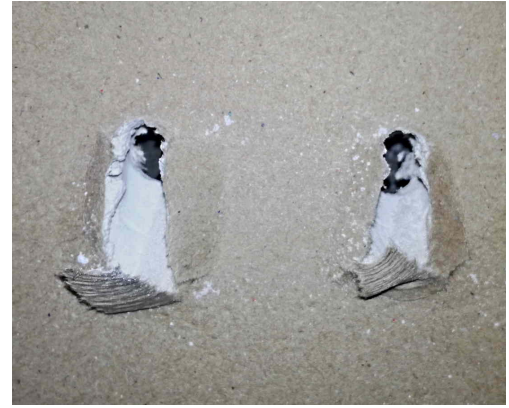

(c)

Figure 30: Illustration of key aspects of failure modes (a) pull-through of screw for double board specimens, (b) bearing and tilting of screw for single board specimens and (c) typical failure surface on the back of the plasterboard 

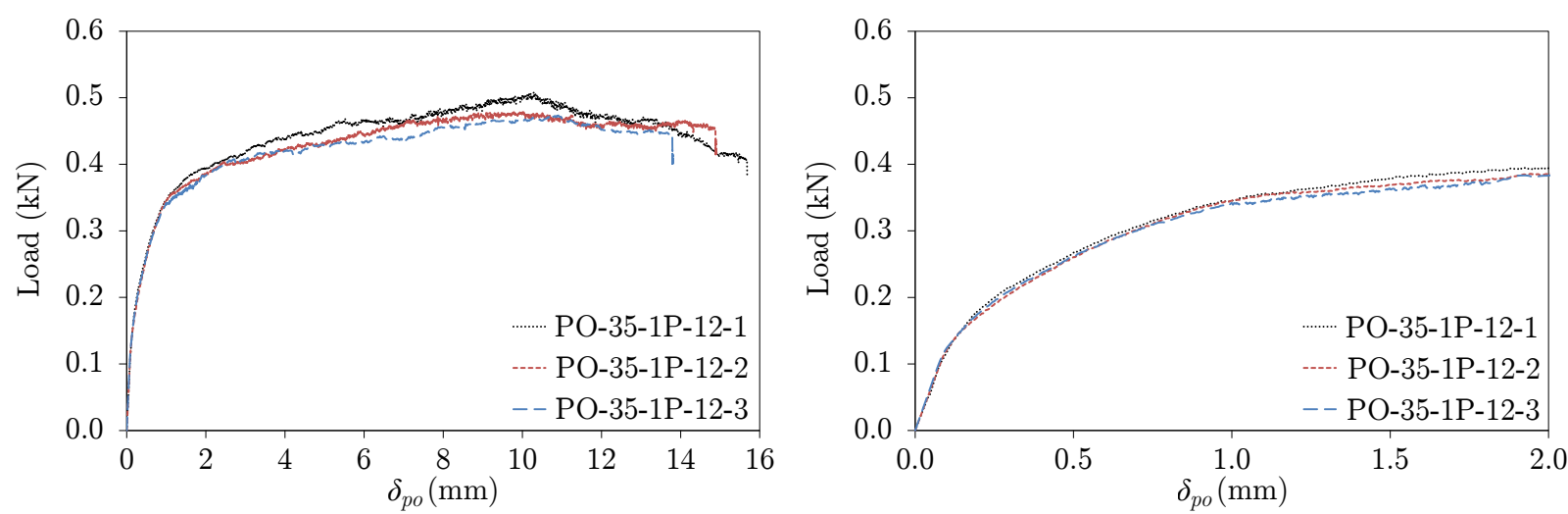

(a1)

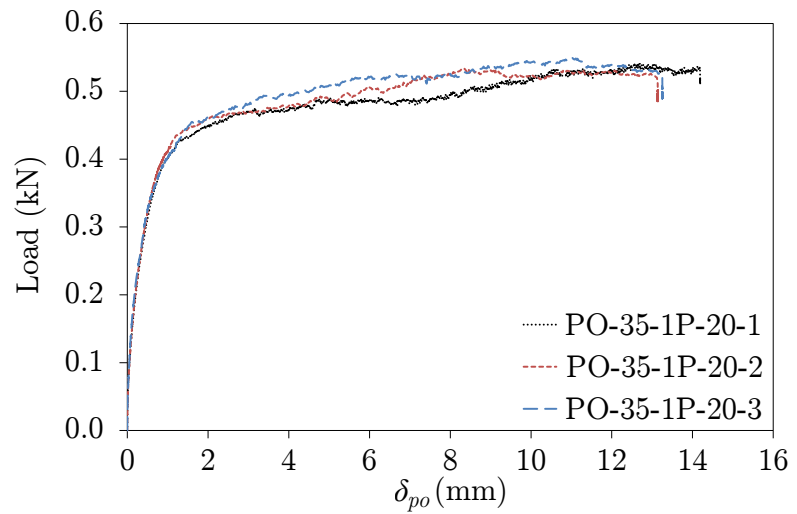

(a2)

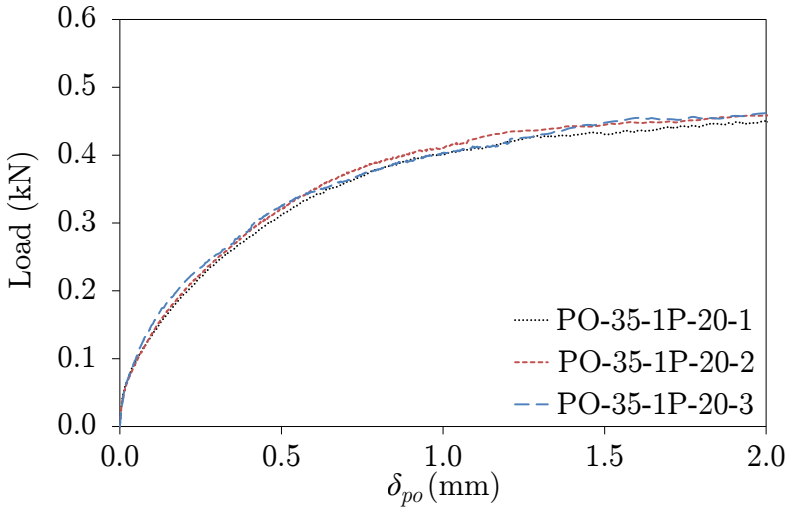

(b1)

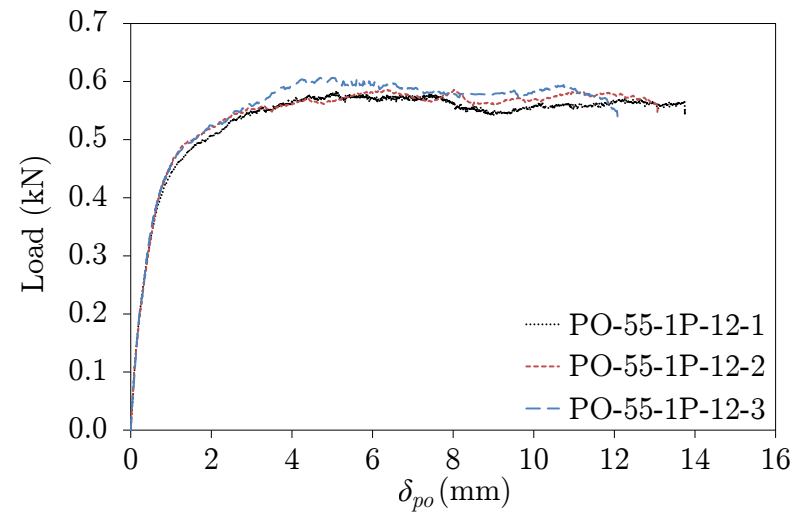

$(\mathrm{c} 1)$

(b2)

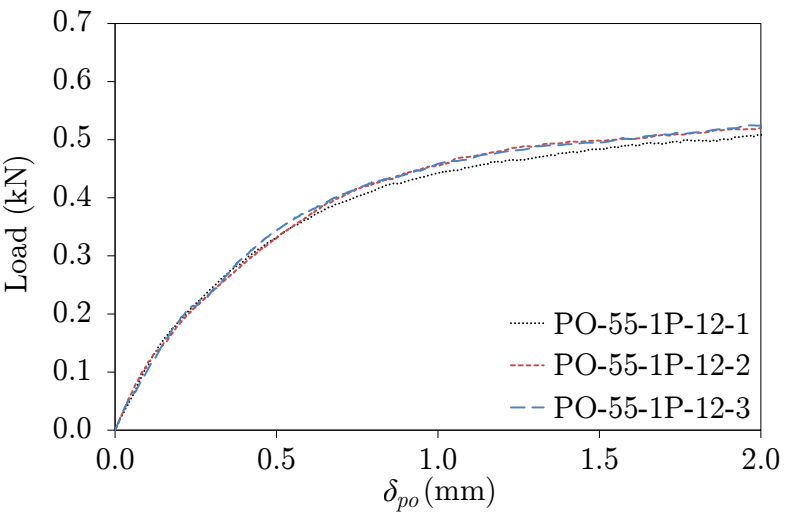

(c2)

Figure 31: Single layer plasterboard push-out load-slip responses, averaged per screw, for (a) PO-35-1P-12, (b) PO-35-1P-20 and (c) PO-55-1P-12 over a horizontal scale up to $16 \mathrm{~mm}$ (a1, b1, c1) and up to $2.0 \mathrm{~mm}$ $(\mathrm{a} 2, \mathrm{~b} 2, \mathrm{c} 3)$ 

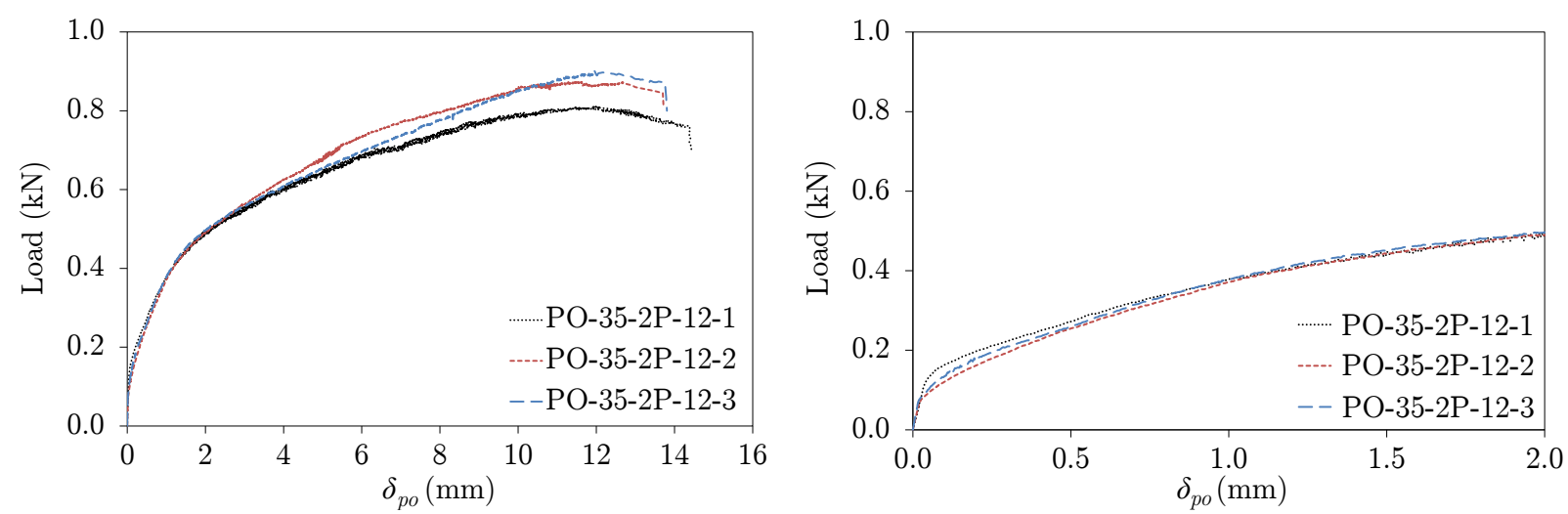

(a1)

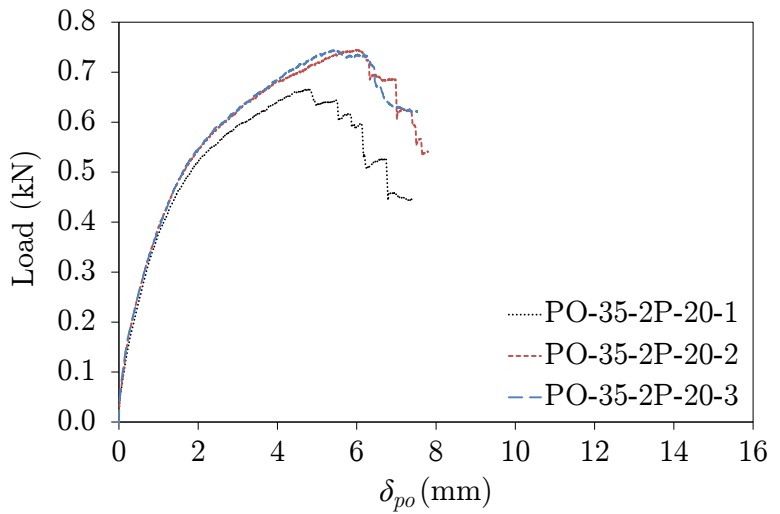

(a2)

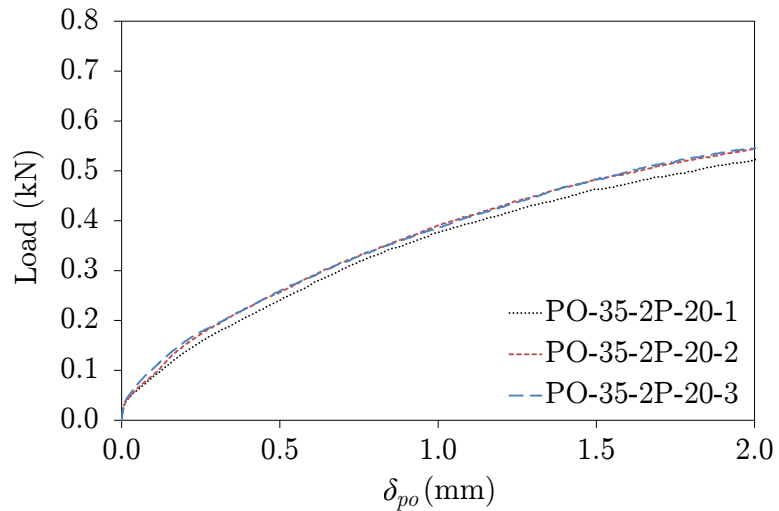

(b1)

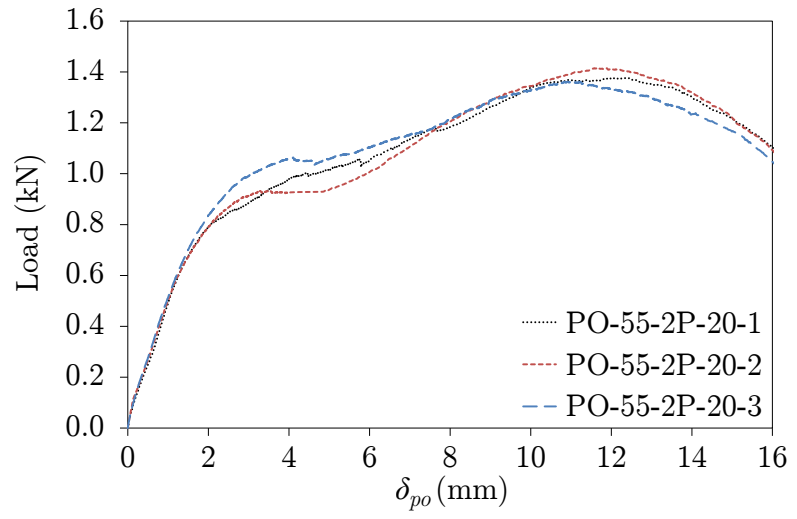

$(\mathrm{c} 1)$

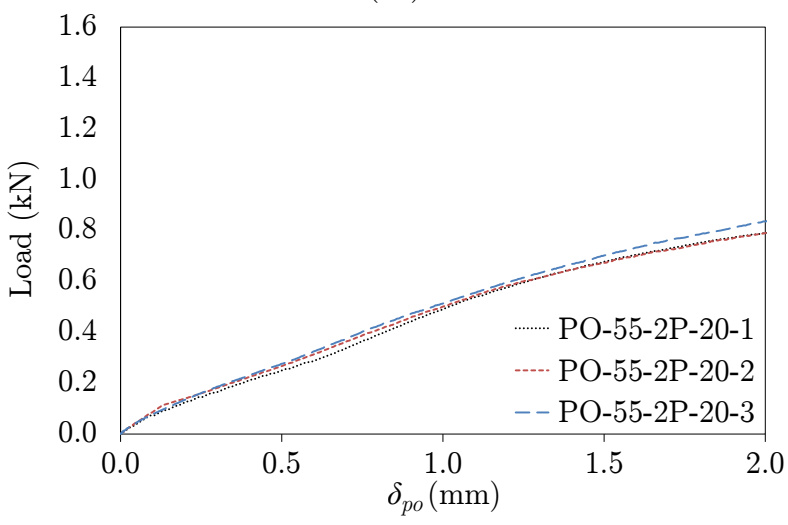

(c2)

Figure 32: Double layer plasterboard push-out load-slip responses, averaged per screw, for (a) PO-35-2P-12, (b) PO-35-2P-20 and (c) PO-55-2P-20 over a horizontal scale up to $16 \mathrm{~mm}$ (a1, b1, c1) and up to $2.0 \mathrm{~mm}$ $(\mathrm{a} 2, \mathrm{~b} 2, \mathrm{c} 3)$ 
Table 15: Measured results from push-out tests on single board specimens

\begin{tabular}{lcccc}
\hline Designation & $K_{o}(\mathrm{kN} / \mathrm{mm})$ & $K_{o, 40}(\mathrm{kN} / \mathrm{mm})$ & $F_{u, p o}(\mathrm{kN})$ & $\delta_{u, p o}(\mathrm{~mm})$ \\
\hline PO-35-1P-12-1 & 1.11 & 0.78 & 0.51 & 10.3 \\
PO-35-1P-12-2 & 1.19 & 0.75 & 0.48 & 9.97 \\
PO-35-1P-12-3 & 1.13 & 0.80 & 0.47 & 10.7 \\
Average & 1.14 & 0.77 & 0.49 & 10.3 \\
COV & 0.04 & 0.03 & 0.04 & 0.04 \\
\hline PO-35-1P-20-1 & 3.51 & 0.90 & 0.54 & 12.7 \\
PO-35-1P-20-2 & 3.11 & 0.95 & 0.53 & 8.35 \\
PO-35-1P-20-3 & 3.35 & 1.03 & 0.55 & 11.0 \\
Average & 3.32 & 0.96 & 0.54 & 10.7 \\
COV & 0.06 & 0.07 & 0.01 & 0.20 \\
\hline PO-55-1P-12-1 & 1.03 & 0.84 & 0.58 & 5.10 \\
PO-55-1P-12-2 & 1.10 & 0.80 & 0.59 & 6.33 \\
PO-55-1P-12-3 & 0.99 & 0.80 & 0.61 & 5.02 \\
Average & 1.04 & 0.81 & 0.59 & 5.48 \\
COV & 0.05 & 0.03 & 0.02 & 0.13 \\
\hline
\end{tabular}


Table 16: Measured results from push-out tests on double board specimens

\begin{tabular}{lcccc}
\hline Designation & $K_{o}(\mathrm{kN} / \mathrm{mm})$ & $K_{o, 40}(\mathrm{kN} / \mathrm{mm})$ & $F_{u, p o}(\mathrm{kN})$ & $\delta_{u, p o}(\mathrm{~mm})$ \\
\hline PO-35-2P-12-1 & 2.88 & 0.45 & 0.81 & 11.9 \\
PO-35-2P-12-2 & 1.79 & 0.39 & 0.87 & 11.4 \\
PO-35-2P-12-3 & 2.11 & 0.40 & 0.90 & 12.0 \\
Average & 2.26 & 0.41 & 0.86 & 11.8 \\
COV & 0.25 & 0.08 & 0.05 & 0.03 \\
\hline PO-35-2P-20-1 & 0.91 & 0.46 & 0.67 & 4.72 \\
PO-35-2P-20-2 & 0.89 & 0.47 & 0.75 & 6.02 \\
PO-35-2P-20-3 & 1.22 & 0.47 & 0.75 & 5.45 \\
Average & 1.00 & 0.47 & 0.72 & 5.40 \\
COV & 0.18 & 0.02 & 0.06 & 0.12 \\
\hline PO-55-2P-20-1 & 0.50 & 0.48 & 1.38 & 12.0 \\
PO-55-2P-20-2 & 0.57 & 0.49 & 1.42 & 11.7 \\
PO-55-2P-20-3 & 0.53 & 0.51 & 1.36 & 11.2 \\
Average & 0.54 & 0.49 & 1.38 & 11.6 \\
COV & 0.06 & 0.02 & 0.02 & 0.03 \\
\hline
\end{tabular}

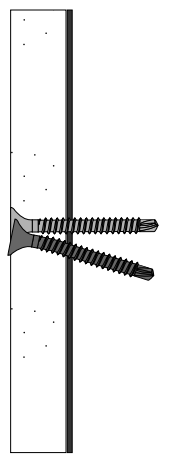

(a)

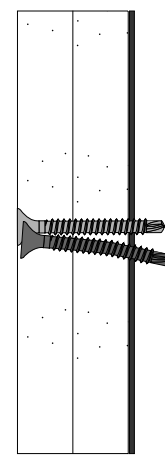

(b)

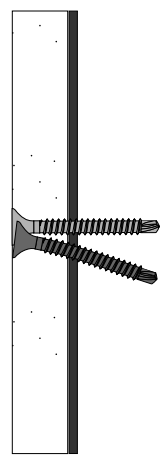

(c)

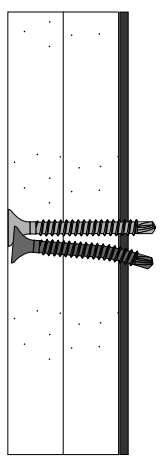

(d)

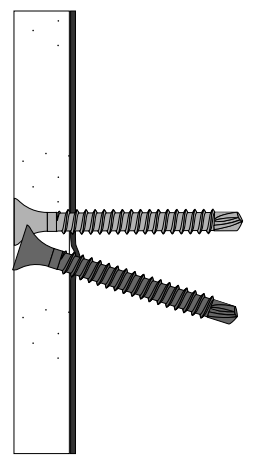

(e)

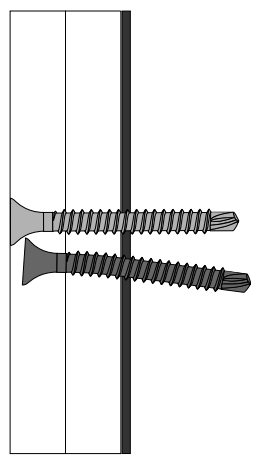

(f)

Figure 33: Illustrations of the observed failure modes for (a) PO-35-1P-12, (b) PO-35-2P-12, (c) PO-35-1P20, (d) PO-35-2P-20, (e) PO-55-1P-12 and (f) PO-55-2P-20 specimens 
Table 17: Average measured results from push-out tests

\begin{tabular}{cccccc}
\hline Designation & $\begin{array}{c}K_{o} \\
(\mathrm{kN} / \mathrm{mm})\end{array}$ & $\begin{array}{c}K_{o, 40} \\
(\mathrm{kN} / \mathrm{mm})\end{array}$ & $\begin{array}{c}F_{u, p o} \\
(\mathrm{kN})\end{array}$ & $\begin{array}{c}\delta_{u, p o} \\
(\mathrm{~mm})\end{array}$ & Failure mode \\
\hline PO-35-1P-12 & 1.14 & 0.77 & 0.49 & 10.3 & $\mathrm{~T}+\mathrm{B}$ \\
PO-35-2P-12 & 2.26 & 0.41 & 0.86 & 11.8 & $\mathrm{~T}+\mathrm{PT} \rightarrow \mathrm{M}$ \\
PO-35-1P-20 & 3.32 & 0.96 & 0.54 & 10.7 & $\mathrm{~T}+\mathrm{B}$ \\
PO-35-2P-20 & 1.34 & 0.47 & 0.72 & 5.40 & $\mathrm{~T}+\mathrm{PT} \rightarrow \mathrm{M} \rightarrow \mathrm{S}$ \\
PO-55-1P-12 & 1.04 & 0.81 & 0.59 & 5.48 & $\mathrm{~T}+\mathrm{B}$ \\
PO-55-2P-20 & 0.54 & 0.49 & 1.38 & 11.6 & $\mathrm{~T}+\mathrm{PT} \rightarrow \mathrm{M}$ \\
\hline
\end{tabular}

$\mathrm{T}=$ tilting; $\mathrm{B}=$ bearing; $\mathrm{PT}=$ pull-through; $\mathrm{M}=$ bending of screw; $\mathrm{S}=$ shear failure of screw

\section{Assemblage of experimental database}

Experimental data from the literature, to complement those reported herein, have been collected. The combined dataset are utilised for the development and assessment of predictive models in the companion paper [28]. Data from material tests on cold-formed steel have not been collected since a detailed review and development of a predictive model for the description of stress-strain curves for cold-formed steels has been recently performed in 4], where more than 700 experimental stress-strain curves were collected and analysed. Similarly, in [40], more than 500 stress-strain curves for hot-rolled steel were assessed and predictive models were developed. Also, no data were found in the literature for the individual mode of screw pull-through in plasterboard or OSB. Data collection was therefore focused on plasterboard and OSB material and the behaviour of screw connectors in shear.

\subsection{Data on material behaviour}

\subsubsection{Plasterboard}

A summary of the experimental data on the material properties of standard type plasterboard, both from the the current study and collected from the literature is presented in Table 18, along with the number of tests from each source. The average material properties 
are provided in the Table 18, while the individual stress-strain curves are examined in the companion paper [28]. The employed notation is as defined in Section 2.2.

In the experimental studies reported in [7], tests were performed on five different types of plasterboard, two of which are considered to be standard and have hence been included in Table 18. Three tensile coupons of $12.5 \mathrm{~mm}$ and $15.0 \mathrm{~mm}$ thick standard plasterboard tested in the longitudinal direction were reported in [8] as part of an experimental investigation on stud walls. For all the gathered experimental data, full stress-strains curves were provided and are examined in the companion paper.

Table 18: Summary of key average material properties from the present study and the literature on standard plasterboard

\begin{tabular}{lccccccccccc}
\hline & & \multicolumn{1}{c}{ Tension } & \multicolumn{7}{c}{ Compression } \\
Source & Thickness & Density & No. of & $E$ & $f_{u}$ & $\varepsilon_{u}$ & No. of & $E$ & $f_{u}$ & $\varepsilon_{u}$ & $\varepsilon_{u, 0.8}$ \\
& $(\mathrm{~mm})$ & $\left(\mathrm{kg} / \mathrm{m}^{3}\right)$ & tests & $(\mathrm{MPa})$ & $(\mathrm{MPa})$ & $(\%)$ & tests & $(\mathrm{MPa})$ & $(\mathrm{MPa})$ & $(\%)$ & $(\%)$ \\
\hline Longitudinal & & & & & & & & & & \\
Present study & 12.5 & 665 & 5 & 1650 & 1.45 & 0.61 & 4 & 2110 & 3.81 & 0.23 & 0.37 \\
Petrone et al. [7] & 12.5 & 720 & 15 & 1940 & 1.86 & 0.98 & 14 & 2470 & 3.28 & 0.19 & 0.36 \\
Petrone et al. [7] & 18.0 & 862 & 16 & 4630 & 1.56 & 0.74 & 16 & 3310 & 5.48 & 0.22 & 0.28 \\
Selvaraj et al. [8] & 12.5 & $\mathrm{NR}$ & 3 & 2100 & 1.29 & 0.96 & - & - & - & - & - \\
Selvaraj et al. [8] & 15.0 & $\mathrm{NR}$ & 3 & 2270 & 1.40 & 0.90 & - & - & - & - & - \\
Transverse & & & & & & & & & & & \\
Present study & 12.5 & 665 & 5 & 1670 & 0.67 & 0.38 & 4 & 2130 & 3.33 & 0.23 & 0.42 \\
Petrone et al. [7] & 12.5 & 720 & 16 & 1540 & 0.80 & 0.45 & 16 & 2130 & 3.02 & 0.30 & 0.65 \\
Petrone et al. [7] & 18.0 & 862 & 15 & 3900 & 0.68 & 0.20 & 15 & 3080 & 4.94 & 0.22 & 0.31 \\
\hline NR = not reported & & & & & & & & & &
\end{tabular}

\subsection{2. $O S B$}

A summary of the experimental data on the material properties of orientated strand boards (OSB), both from the current study and from the literature [9-11], are presented in Table 19. The number of tests and average properties from each source are reported along with the number (in brackets) of the available full stress-strain $(\sigma-\varepsilon)$ curves, which are examined individually in the companion paper [28]. A database of 120 stress-strain 
curves for $9.5 \mathrm{~mm}$ thick OSB is reported in [9] for specimens tested both in tension and compression, cut at $0^{\circ}, 45^{\circ}$ and $90^{\circ}$ to the direction of production of the board. Tests along these three directions were also performed in tension only in [10] and in both compression and tension in [11]. In [10], no stress-strain curves are provided, but the mean values of Young's modulus and strength are reported for the core and outer surfaces of an $18 \mathrm{~mm}$ thick type 3 OSB (OSB/3); the properties reported in Table 19 are those of the outer surfaces. Similarly, average properties are reported in [11], with only two stress-strain curves provided as typical examples in the longitudinal direction, both for tension and compression.

Characteristic values of key design properties such as density, Young's modulus and ultimate strengths in bending, compression and tension, both parallel and perpendicular to the direction of production of the board, for thicknesses of less than $25 \mathrm{~mm}$ are provided in EN 12369-1 [41]. In Table 19 the relevant properties for OSB/3, for thicknesses between 10 $\mathrm{mm}$ and $18 \mathrm{~mm}$ are provided for comparison with the the results of this study and the data gathered from the literature.

The results of the current study in tension are generally consistent with those reported in the literature, whereas in compression, the obtained values of strength are approximately $5-15 \%$ lower than the results from the literature. The tensile strength in the longitudinal direction given in EN 12369-1 41] is approximately 20\% lower compared to the results from the current study and literature. On the other hand, the compressive strength reported in EN 12369-1 [41] is approximately 10\% higher compared to the data reported in the literature and 20-25\% higher compared to the results of this study, both for the longitudinal and transverse load directions. 
Table 19: Summary of key average material properties from the present study and the literature on OSB

\begin{tabular}{|c|c|c|c|c|c|c|c|c|c|c|c|}
\hline \multirow[b]{2}{*}{ Source } & \multirow[b]{2}{*}{$\begin{array}{c}\text { Thickness } \\
\text { (mm) }\end{array}$} & \multirow[b]{2}{*}{$\begin{array}{l}\text { Density } \\
\left(\mathrm{kg} / \mathrm{m}^{3}\right)\end{array}$} & \multicolumn{4}{|c|}{ Tension } & \multicolumn{5}{|c|}{ Compression } \\
\hline & & & $\begin{array}{l}\text { No. of tests } \\
(\sigma-\varepsilon \text { curves })\end{array}$ & $\begin{array}{c}E \\
(\mathrm{MPa})\end{array}$ & $\begin{array}{c}f_{u} \\
(\mathrm{MPa})\end{array}$ & $\begin{array}{c}\varepsilon_{u} \\
(\%)\end{array}$ & $\begin{array}{l}\text { No. of tests } \\
(\sigma-\varepsilon \text { curves })\end{array}$ & $\begin{array}{c}E \\
(\mathrm{MPa})\end{array}$ & $\begin{array}{c}f_{u} \\
(\mathrm{MPa})\end{array}$ & $\begin{array}{l}\varepsilon_{u} \\
(\%)\end{array}$ & $\begin{array}{r}\varepsilon_{u, 0.8} \\
(\%)\end{array}$ \\
\hline \multicolumn{12}{|l|}{ Longitudinal } \\
\hline Present study & 11 & 590 & $5(5)$ & 4100 & 11.7 & 0.37 & $4(4)$ & 4020 & 12.1 & 0.40 & 0.54 \\
\hline Chen and He 9] & 9.5 & 580 & $20(20)$ & 3160 & 12.1 & 0.38 & $20(20)$ & 3250 & 13.6 & 0.55 & 0.65 \\
\hline Plenzler et al. 10. & 18 & 594 & $5(\mathrm{NR})$ & 5150 & 11.2 & NR & - & - & - & - & - \\
\hline Zhu et al. 11] & 9 & 575 & $8(1)$ & 3770 & 11.9 & 0.39 & $5(1)$ & 3650 & 14.1 & 0.58 & 0.78 \\
\hline EN 12369-1 41] & $10-18$ & 550 & $\mathrm{NR}$ & 3800 & 9.4 & NR & NR & 3800 & 15.4 & NR & NR \\
\hline \multicolumn{12}{|l|}{ Transverse } \\
\hline Present study & 11 & 590 & $5(5)$ & 2940 & 7.01 & 0.37 & $4(4)$ & 2780 & 10.7 & 0.50 & 0.66 \\
\hline Chen and He [9] & 9.5 & 580 & $20(20)$ & 2330 & 9.7 & 0.42 & $20(20)$ & 2490 & 11.3 & 0.61 & 0.70 \\
\hline Plenzler et al. 10] & 18 & 594 & $5(\mathrm{NR})$ & 3720 & 6.15 & NR & - & - & - & - & - \\
\hline Zhu et al. 11] & 9 & 575 & $8(\mathrm{NR})$ & 2560 & 7.55 & 0.29 & $5(\mathrm{NR})$ & 2770 & 12.6 & NR & $\mathrm{NR}$ \\
\hline $\begin{array}{l}\text { EN } 12369-1 \text {, } \\
\text { at } 45^{\circ}\end{array}$ & $10-18$ & 550 & NR & 3000 & 7.0 & NR & NR & 3000 & 12.7 & $\mathrm{NR}$ & NR \\
\hline Chen and He 9] & 9.5 & 580 & $20(20)$ & 2760 & 10.9 & 0.39 & $20(20)$ & 2770 & 12.5 & 0.57 & 0.66 \\
\hline Plenzler et al. [10 & 18 & 594 & $5(\mathrm{NR})$ & 4850 & 5.84 & NR & - & - & - & - & - \\
\hline Zhu et al. 11] & 9 & 575 & $8(\mathrm{NR})$ & 3170 & 9.14 & 0.29 & $5(\mathrm{NR})$ & 3100 & 13.9 & NR & NR \\
\hline
\end{tabular}

\subsection{Shear behaviour}

Test data on the shear behaviour of screws connecting boards to cold-formed steel have been collected from the literature based on the following three conditions. Firstly, only standard plasterboard and OSB were considered. Secondly, tests in which the screws were located near to the edge or end of the board, leading to the board breaking away [14, 16, 18, 20 22], were ignored; all other failure modes were considered. Finally, data obtained from both push and pull tests were considered but only under monotonic loading.

A summary of the key details and average results from the shear behaviour tests featuring screwed connections between cold-formed steel and plasterboard or oriented strand board collected from the literature [14, 17, 19, 22, 38] is presented in Table 20, along with the results of the current study. The data from a total of 51 tests on plasterboard specimens from seven different sources and 42 tests on OSB specimens from five different sources were 
collected. Full load-displacement $(F-\delta)$ curves were available for 42 of the plasterboard tests and 24 of the OSB tests, which allowed calculation of properties such as the initial stiffness $K_{o}$ (as described in Section 4.2 and the analysis of the form of the response, as examined in the companion paper 28]. For each group of tests, along with the number of test data from each source and the average measured properties $\left(F_{u, p o}, \delta_{u, p o}, K_{o, 40}\right.$ and $\left.K_{o}\right)$, key details for each group of tests are provided, such as the diameter of the screws and the thicknesses of the steel sections and boards. The observed failure modes are also provided.

Some comments on the data collection follow. The pull tests performed in [17 and [20] with connectors spaced at different distances apart were grouped together since the variation in spacing between the connectors did not have a strong effect on the results, while the tests performed in [20] with overdriven screws and those that examined the influence of the humidity content of the board were excluded. For the tests reported in [21], only the room temperature specimens, and not those subjected to elevated temperatures were considered

Regarding the observed modes of failure, for tests comprising a single layer plasterboard, the main failure mode was tilting of the screws and subsequent bearing into the material. On the other hand, for the OSB test specimens, bending of the screws was shown to be the principal mode of failure after some initial tilting and bearing into the material. Tilting of the screws generally arises in specimens with weaker and thinner board material while screw bending occurs when the board is sufficiently strong or thick to restrict tilting and hence enforce flexure of the screws. The thickness of the steel also plays a role, with thicker material restricting tilting of the screws [39]. For the groups of tests in the current study employing two layers of plasterboard, screw bending was dominant. Pull-through usually developed eventually in all cases, following the types of failure mentioned above, for both the plasterboard and OSB specimens.

As described in Section 4.2, the test specimens with two layers of plasterboard, $2.0 \mathrm{~mm}$ thick steel and $3.5 \mathrm{~mm}$ screws all featured failure of the screws in shear. Peterman et al. [17] reported similar shear failures of the screws in specimens with $4.8 \mathrm{~mm}$ diameter screws connecting OSB material to $2.46 \mathrm{~mm}$ thick steel. In both studies (i.e. the present study and 
[17]), when the same tests were repeated using thinner steel sections, the ultimate load was higher and shearing of the screw did not occur. Although further investigation is needed to support this, it appears that when the steel is thick enough (at least half the diameter of the screw connector) and the board is sufficiently strong (either through material strength or thickness), shearing of the screw can occur as a result of high shear, coupled with bending and axial tension in the screw.

From the collected data, it can be observed that the average stiffness calculated at $40 \%$ of the peak load $K_{o, 40}$ varies between about 0.4 and $1.8 \mathrm{kN} / \mathrm{mm}$ for the plasterboard specimens and between about 0.6 and $1.9 \mathrm{kN} / \mathrm{mm}$ for the OSB specimens. The average initial stiffness $K_{o}$ can be seen to be consistently higher than $K_{o, 40}$ for all test specimens, indicating early nonlinearity of the load-displacement curves.

The ultimate capacities of the specimens with a single board and $3.5 \mathrm{~mm}$ screws from the current study are generally similar to those reported in the literature [17, 19, 20, 38]. When two layers of plasterboard are used, increases in capacities of up to $75 \%$ over equivalent setups with a single layer of plasterboard were found in both the present study and the literature [21]. The average ultimate capacities from the present study and the literature for the OSB specimens are about three to four times higher than the respective plasterboard specimens; this is attributed to the higher stiffness and strength of the OSB, which changes the main failure mode from tilting to bending of the screw. Displacements at the ultimate capacities $\delta_{u, p o}$ can be seen to be rather variable from the collected data. For the plasterboard data, the shear push-out test specimens, examined in this study, exhibited $\delta_{u, p o}$ values in excess of $10 \mathrm{~mm}$, whereas the pull-out test specimens, the results of which were collected from the literature [17, 19, 21, 22], tend to exhibit lower $\delta_{u, p o}$ values, ranging between $2-7$ $\mathrm{mm}$. 
Table 20: Summary of key average results from shear behaviour tests from the present study and the literature

\begin{tabular}{|c|c|c|c|c|c|c|c|c|c|c|}
\hline Source & $\begin{array}{l}\text { No. of } \\
\text { tests }\end{array}$ & $\begin{array}{c}\text { Full } F-\delta \\
\text { curves }\end{array}$ & $\begin{array}{l}\text { Screw diameter } \\
(\mathrm{mm})\end{array}$ & $\begin{array}{l}\text { Steel thickness } \\
\qquad(\mathrm{mm})\end{array}$ & $\begin{array}{l}\text { Board thickness } \\
\qquad(\mathrm{mm})\end{array}$ & $\begin{array}{l}F_{u, p o} \\
(\mathrm{kN})\end{array}$ & $\begin{array}{c}\delta_{u, p o} \\
(\mathrm{~mm})\end{array}$ & $\begin{array}{c}K_{o, 40} \\
(\mathrm{kN} / \mathrm{mm})\end{array}$ & $\begin{array}{c}K_{o} \\
(\mathrm{kN} / \mathrm{mm})\end{array}$ & Failure mode \\
\hline \multicolumn{11}{|l|}{ Plasterboard } \\
\hline \multirow[t]{6}{*}{ Present study } & 3 & 3 & 3.5 & 1.2 & 12.5 & 0.49 & 10.3 & 0.77 & 1.14 & $\mathrm{~T}+\mathrm{B}$ \\
\hline & 3 & 3 & 3.5 & 1.2 & $2 \times 12.5$ & 0.86 & 11.8 & 0.41 & 2.26 & $\mathrm{~T}+\mathrm{PT} \rightarrow \mathrm{M}$ \\
\hline & 3 & 3 & 3.5 & 2.0 & 12.5 & 0.54 & 10.7 & 0.96 & 3.32 & $\mathrm{~T}+\mathrm{B}$ \\
\hline & 3 & 3 & 3.5 & 2.0 & $2 \times 12.5$ & 0.72 & 5.40 & 0.47 & 1.00 & $\mathrm{~T}+\mathrm{PT} \rightarrow \mathrm{M} \rightarrow \mathrm{S}$ \\
\hline & 3 & 3 & 5.5 & 1.2 & 12.5 & 0.59 & 5.48 & 0.81 & 1.04 & $\mathrm{~T}+\mathrm{B}$ \\
\hline & 3 & 3 & 5.5 & 2.0 & $2 \times 12.5$ & 1.38 & 11.6 & 0.49 & 0.54 & $\mathrm{~T}+\mathrm{PT} \rightarrow \mathrm{M}$ \\
\hline \multirow[t]{3}{*}{ Peterman et al. [17] } & 4 & 4 & 3.5 & 0.84 & 12.7 & 0.51 & 7.49 & 0.61 & 0.63 & $\mathrm{~T}+\mathrm{B}+\mathrm{PT}$ \\
\hline & 4 & 4 & 3.5 & 1.37 & 12.7 & 0.56 & 6.48 & 0.61 & 0.70 & $\mathrm{~T}+\mathrm{B}+\mathrm{PT}$ \\
\hline & 4 & 4 & 3.5 & 2.46 & 12.7 & 0.48 & 4.19 & 0.74 & 1.03 & $\mathrm{~T}+\mathrm{B}+\mathrm{PT}$ \\
\hline Fiorino et al. 19] & 6 & 2 & 3.5 & 1.0 & 12.5 & 0.60 & 4.28 & 1.77 & 2.49 & $\mathrm{~T}+\mathrm{PT}$ \\
\hline \multirow[t]{2}{*}{ Ye et al. 22} & 6 & 4 & 4.8 & 0.9 & 12.5 & 0.75 & 3.77 & 0.69 & 0.82 & $\mathrm{~T}+\mathrm{B}$ \\
\hline & 2 & NR & 4.8 & 1.2 & 12.5 & 0.79 & 3.5 & NR & NR & $\mathrm{T}+\mathrm{B}$ \\
\hline \multirow[t]{2}{*}{ Chen et al. 21] } & 1 & 1 & 4.2 & 1.00 & 12.5 & 0.72 & 1.35 & 0.99 & 1.07 & $\mathrm{~T}+\mathrm{B}$ \\
\hline & 1 & 1 & 4.2 & 1.00 & $2 \times 12.5$ & 1.04 & 1.87 & 1.17 & 1.20 & $\mathrm{~T}+\mathrm{B}$ \\
\hline Stergiopoulos et al. 38 & 1 & NR & 3.5 & 1.2 & 12.5 & 0.5 & NR & 0.54 & NR & $\mathrm{T}+\mathrm{B}+\mathrm{PT}$ \\
\hline \multicolumn{11}{|l|}{ OSB } \\
\hline \multirow[t]{3}{*}{ Peterman et al. [17] } & 4 & 4 & 4.8 & 0.84 & 11.1 & 1.98 & 7.62 & 0.85 & 1.50 & $\mathrm{~T}+\mathrm{M}+\mathrm{PT}$ \\
\hline & 4 & 4 & 4.8 & 1.37 & 11.1 & 2.16 & 6.73 & 1.52 & 1.95 & $\mathrm{~T}+\mathrm{M}+\mathrm{PT}$ \\
\hline & 5 & 4 & 4.8 & 2.46 & 11.1 & 1.66 & 2.49 & 1.90 & 2.33 & $\mathrm{~B}+\mathrm{M}+\mathrm{S}$ \\
\hline Fiorino et al. [19] & 16 & 4 & 4.2 & 1.0 & 9 & 1.69 & 5.60 & 1.05 & 2.26 & $\mathrm{~T}+\mathrm{M}+\mathrm{PT}$ \\
\hline Vieira and Schafer 20 & 1 & 1 & 4.8 & 1.81 & 11.1 & 2.35 & 8.13 & 1.19 & 1.42 & $\mathrm{~T}+\mathrm{M}$ \\
\hline Ye et al. 22 & 6 & 4 & 4.8 & 0.9 & 18 & 1.98 & 9.27 & 0.50 & 0.62 & $\mathrm{~T}+\mathrm{B}+\mathrm{M}$ \\
\hline Serrette et al. [14 & 3 & NR & 3.5 & 0.88 & 11.1 & 1.03 & NR & NR & NR & $\mathrm{T}+\mathrm{B}+\mathrm{M}+\mathrm{PT}$ \\
\hline Total: & 86 & 59 & & & & & & & & \\
\hline
\end{tabular}

\section{Conclusions}

An experimental investigation into the material response of, and interaction between, the different components of a typical sheathed cold-formed steel wall system has been presented. A total of 103 material and component tests was performed, covering tensile tests on cold-formed steel coupons, compressive and tensile material tests on OSB and plasterboard coupons (extracted from both the longitudinal and transverse board directions), tensile and shear screw connector tests and, finally, pull-through and push-out (shear) tests to examine the behaviour of screwed steel-to-board connections.

The material tests conducted on plasterboard revealed that, although the values of 
Young's modulus and compressive strength were similar for the longitudinal and transverse directions, the ultimate tensile stress in the longitudinal direction was substantially higher than in the transverse direction. Also, the mechanical properties of the plasterboard material in compression were found to be higher than in tension.

The response of the OSB material was found to be influenced significantly by the direction of loading relative to the production direction of the board, with higher values of Young's modulus and strength measured in the longitudinal direction compared to the transverse direction. This anisotropy is related to the orientation of the strands in the OSB, which are generally parallel to the direction of production (i.e. the longitudinal direction).

Addressing a lack of relevant test data in the literature, a series of pull-through experiments was conducted, featuring different types of screws and sheathing boards - OSB and plasterboards, with the latter board type studied in both single and double layer arrangements. The shape of the underside of the screw head was found to have a significant influence on the pull-through response, with flatter heads resulting in delayed cutting of the paper at the board surface and hence in improved ductility. Using two layers of plasterboard led to average increases of $60 \%$ in stiffness and $30 \%$ in strength, when compared to a single plasterboard layer. The specimens with the OSB sheathing reached ultimate capacities of about three times those attained by the single layer plasterboard specimens.

To investigate the shear behaviour of screwed connections between cold-formed steel sections and sheathing boards, push-out tests were undertaken, with the varied parameters being the screw size, the number of board layers and the steel thickness. The shear strength of the connection was found to increase with increasing steel thickness, screw diameter and number of plasterboard layers. The main failure modes were screw tilting and screw bending, with the latter mode being more prominent in the specimens with the stronger and thicker boards.

Finally, experimental data from the literature, to complement those reported in the present paper, have been collected and discussed. In the companion paper, the combined dataset is employed for the development and assessment of analytical models to describe the observed mechanical responses of the material and components in sheathed cold-formed 
steel wall systems.

\section{Acknowledgements}

Les Clark. Funding for this research was received from the EPSRC Centre for Doctoral Training in Sustainable Civil Engineering at Imperial College London and Ayrshire Metals Limited.

\section{References}

[1] L. C. M. Vieira Junior, B. W. Schafer, Lateral stiffness and strength of sheathing braced cold-formed steel stud walls, Engineering Structures 37 (2012) 205-213.

[2] K. D. Peterman, B. W. Schafer, Sheathed cold-formed steel studs under axial and lateral load, Journal of Structural Engineering 140 (10) (2014) 04014074.

[3] R. M. Lawson, A. G. Way, M. Heywood, J. B. P. Lim, R. Johnston, K. Roy, Stability of light steel walls in compression with plasterboards on one or both sides, Proceedings of the Institution of Civil Engineers-Structures and Buildings (2019) 1-19.

[4] L. Gardner, X. Yun, Description of stress-strain curves for cold-formed steels, Construction and Building Materials 189 (2018) 527-538.

[5] P. Kyvelou, L. Gardner, D. A. Nethercot, Testing and analysis of composite cold-formed steel and wood- based flooring systems, Journal of Structural Engineering 143 (11) (2017) 04017146.

[6] L. C. M. Vieira Junior, Y. Shifferaw, B. W. Schafer, Experiments on sheathed cold-formed steel studs in compression, Journal of Constructional Steel Research 67 (10) (2011) 1554-1566.

[7] C. Petrone, G. Magliulo, G. Manfredi, Mechanical properties of plasterboards: experimental tests and statistical analysis, Journal of Materials in Civil Engineering 28 (11) (2016) 04016129.

[8] S. Selvaraj, M. Madhavan, Investigation on sheathing effect and failure modes of gypsum sheathed cold-formed steel wall panels subjected to bending, Structures 17 (2019) 87-101.

[9] G. Chen, B. He, Stress-strain constitutive relation of osb under axial loading: An experimental investigation, BioResources 12 (3) (2017) 6142-6156.

[10] R. Plenzler, L. Ludwiczak-Niewiadomska, P. Strzelecki, Elastic and strength properties of OSB layers, Drvna industrija: Znanstveni časopis za pitanja drvne tehnologije 68 (1) (2017) 3-9.

[11] E. C. Zhu, Z. W. Guan, P. D. Rodd, D. J. Pope, A constitutive model for OSB and its application in finite element analysis, Holz als Roh-und Werkstoff 63 (2) (2005) 87-93. 
[12] T. H. Miller, T. Pekoz, Behavior of gypsum-sheathed cold-formed steel wall studs, Journal of Structural Engineering 120 (5) (1994) 1644-1650.

[27] S. Selvaraj, M. Madhavan, Sheathing braced design of cold-formed steel structural members subjected 
to torsional buckling, Structures 20 (2019) 489-509.

[28] C. Kyprianou, P. Kyvelou, L. Gardner, D. A. Nethercot, Characterisation of material and connection behaviour in sheathed cold-formed steel wall systems - Part 2: analytical modelling, Structures [Submitted].

[29] EN ISO 6892, Metallic materials - Tensile testing. Part 1: Method of test at room temperature, European Committee for Standardization, Brussels, Belgium (2016).

[30] EN 520, Gypsum plasterboards - Definitions, requirements and test methods, European Committee for Standardization, Brussels, Belgium (2009).

[31] EN 789, Timber structures. Test methods. Determination of mechanical properties of wood based panels, European Committee for Standardization, Brussels, Belgium (2005).

[32] DaVis, Version 10.0.5.4259, LaVision, Göttingen, Germany (2019).

[33] EN 300, Oriented Strand Boards (OSB) - Definitions, classification and specifications, European Committee for Standardization, Brussels, Belgium (2006).

[34] EN 1995-1-1, Eurocode 5: Design of timber structures - Part 1-1: General - Common rules and rules for buildings, European Committee for Standardization, Brussels, Belgium (2004).

[35] EN 1383, Timber structures - Test methods - Pull through resistance of timber fasteners, European Committee for Standardization, Brussels, Belgium (2016).

[36] EN 14566:2008+A1, Mechanical fasteners for gypsum plasterboard systems - Definitions, requirements and test methods, European Committee for Standardization, Brussels, Belgium (2009).

[37] EN 1994-1-1, Eurocode 4: Design of composite steel and concrete structures - Part 1-1: General rules and rules for buildings, European Committee for Standardization, Brussels, Belgium (2004).

[38] M. Stergiopoulos, R. M. Lawson, P. Lopez, Composite action of fixings to gypsum boards acting in shear based on material properties, Proceedings of the Institution of Civil Engineers-Construction Materials (2019) $1-56$

[39] N. Vella, L. Gardner, S. Buhagiar, Experimental analysis of cold-formed steel-to-timber connections with inclined screws, Structures 24 (2020) 890-904.

[40] X. Yun, L. Gardner, Stress-strain curves for hot-rolled steels, Journal of Constructional Steel Research 133 (2017) 36-46.

[41] EN 12369-1, Wood-based panels - Characteristic values for structural design - Part 1: OSB, particleboards and fibreboards, European Committee for Standardization, Brussels, Belgium (2001). 